\title{
Status of Growth of Group III-Nitride Heterostructures for Deep Ultraviolet Light-Emitting Diodes
}

\author{
Kai Ding (D), Vitaliy Avrutin, Ümit Özgür and Hadis Morkoç* \\ Department of Electrical and Computer Engineering, Virginia Commonwealth University, 601 West Main Street, \\ Richmond, VA 23284, USA; kding2@vcu.edu (K.D.); vavrutin@vcu.edu (V.A.); uozgur@vcu.edu (Ü.Ö.) \\ * Correspondence: hmorkoc@vcu.edu; Tel.: +1-804-827-3765
}

Academic Editor: Ikai Lo

Received: 4 September 2017; Accepted: 29 September 2017; Published: 4 October 2017

\begin{abstract}
We overview recent progress in growth aspects of group III-nitride heterostructures for deep ultraviolet (DUV) light-emitting diodes (LEDs), with particular emphasis on the growth approaches for attaining high-quality AlN and high Al-molar fraction AlGaN. The discussion commences with the introduction of the current status of group III-nitride DUV LEDs and the remaining challenges. This segues into discussion of LED designs enabling high device performance followed by the review of advances in the methods for the growth of bulk single crystal AlN intended as a native substrate together with a discussion of its UV transparency. It should be stated, however, that due to the high-cost of bulk AlN substrates at the time of writing, the growth of DUV LEDs on foreign substrates such as sapphire still dominates the field. On the deposition front, the heteroepitaxial growth approaches incorporate high-temperature metal organic chemical vapor deposition (MOCVD) and pulsed-flow growth, a variant of MOCVD, with the overarching goal of enhancing adatom surface mobility, and thus epitaxial lateral overgrowth which culminates in minimization the effect of lattice- and thermal-mismatches. This is followed by addressing the benefits of pseudomorphic growth of strained high Al-molar fraction AlGaN on AlN. Finally, methods utilized to enhance both $\mathrm{p}$ - and n-type conductivity of high Al-molar fraction AlGaN are reviewed.
\end{abstract}

Keywords: AlN; AlGaN; deep ultraviolet; light-emitting diodes; MOCVD

\section{Introduction}

With the excellent properties including compactness, low operating power, and long lifetime, deep ultraviolet (DUV) light-emitting diodes (LEDs) and laser diodes (LDs) with wavelengths in the range of 200-350 nm are of great interests for a wide variety of applications. These include, water and air purification, sterilization/disinfection of medical tools, medical diagnostics, phototherapy, polymer curing, and sensing. Among all the wide bandgap semiconductors, group III-nitrides (GaN, AlN, InN, and their ternary and quaternary alloys) are deemed as the most suitable material family for the implementation of DUV LEDs and LDs. This materials family features a wide tunable emission wavelength range covering the entire UVA $(315-400 \mathrm{~nm})$ and UVB $(280-315 \mathrm{~nm})$ regions and part of the UVC (100-280 nm) region with the shortest achievable wavelength of $210 \mathrm{~nm}$ with this materials system. In addition to the continuously tunable band gap, group III-nitrides also have the advantage of some robust physical properties such as high melting point, high thermal conductivity, high mechanical strength, and most importantly, the possibility of achieving both $\mathrm{n}$ - and p-type conduction needed to fabricate a p-n junction diode. During the last decade, a number of groups around the world have been participating in the development of group III-nitrides-based DUV light emitters. Commercial products covering the UVA to UVC range are already available. However, compared with the excellent 
performance achieved in group III-nitride-based LEDs operating in the near UV and visible ranges, the efficiency of DUV LEDs remains rather modest in that, typical external quantum efficiency (EQE) values of deep UV LEDs are around $0.1 \%-10 \%$, depending on the wavelength. Many factors have been identified as limiting the implementation of high-efficiency DUV LEDs, encompassing material growth, light extraction, heat dissipation, etc. Almost all aspects of the DUV devices could undergo substantial improvement.

In this review we focus on the most recent progress in growth approaches of group III-nitride heterostructures for DUV LEDs. First, we give an overview of the current status of group III-nitride UDV LEDs and remaining challenges with special emphasis on the limiting factors in the context of material growth. Then, after overviewing DUV device designs for improved efficiency, we segue into discussion of growth and properties of bulk AlN, which is said to eventually provide the platform for the DUV LEDs. Then, approaches for the growth of AlN and high Al-molar fraction AlGaN epilayers are addressed. Finally, methods utilized to enhance both p- and n-type conductivity of high Al-molar fraction AlGaN are discussed.

\section{Current Status and Challenges of Group III-Nitride DUV LEDs}

Benefiting from the improvements in the crystalline quality of AlN and high Al-molar fraction AlGaN layers, and the optimization of LED structure design, the EQE and output power of AlGaN-based DUV LEDs have increased remarkably in recent years. To enumerate, EQE in near and deep UV LEDs with wavelengths between 220 and $400 \mathrm{~nm}$, developed by several industrial and academic groups, is plotted in Figure 1. In 2010, an EQE of over 3\% and an output power of over $1 \mathrm{~mW}$ at $10 \mathrm{~mA}$ continuous wave (CW) driving were demonstrated in flip-chip DUV LEDs with emission wavelengths between 255 and $280 \mathrm{~nm}$ [1]. Reasonably high IQE near 70\% and an EQE of $1.3 \%$ at $100 \mathrm{~mA}$ forward current were achieved in $260 \mathrm{~nm}$ pseudomorphic UV LEDs on high quality AIN substrates in 2011 [2]. Improvement of the extraction efficiency by die-thinning and encapsulation led to enhancement of the EQE to $4.9 \%$ for $271 \mathrm{~nm}$ LEDs under CW operation [3]. In 2012, a maximum EQE of $10.4 \%$ at $20 \mathrm{~mA} \mathrm{CW}$ current with an output power up to $9.3 \mathrm{~mW}$ for $278 \mathrm{~nm}$ DUV LEDs was achieved through migration-enhanced metal organic chemical vapor deposition (MEMOCVD) to reduce the threading dislocation density (TDD) and by using transparent p-type cladding and contact layers, UV reflecting ohmic contacts, and optimized chip encapsulation [4]. In 2015, a 265 $\mathrm{nm}$ DUV LED with an output power density above $90 \mathrm{~mW} / \mathrm{cm}^{2}$ based on extraction enhancement was reported [5]. In this study, to mitigate the effect of total internal reflection at the AlN surface and the strong absorption of the contact layers, a hybrid structure consisting of photonic crystals and sub-wavelength nanostructures was patterned on the backside of the AlN substrate. A maximum light extraction enhancement of $19.6 \%$ was obtained in comparison to that of a flat AlN substrate surface device, resulting in an EQE of $6.3 \%$ [5]. To avoid absorption by the p-contact and the p-electrode, researchers replaced $\mathrm{p}-\mathrm{GaN}$ by transparent $\mathrm{p}-\mathrm{AlGaN}$ as the $\mathrm{p}$-contact layer, and replaced $\mathrm{Ni} / \mathrm{Au}$ with $\mathrm{Ni}(1 \mathrm{~nm}) / \mathrm{Al}$ as the p-electrode to enhance the reflectivity. In the process, an enhancement of EQE from $2 \%$ to $5.5 \%$ in $287 \mathrm{~nm}$ LEDs grown on sapphire, and a maximum EQE value of $10.8 \%$ under $5 \mathrm{~mA}$ operating current in $276 \mathrm{~nm}$ LEDs were reported [6,7]. In 2017, an EQE of 20.3\% under $20 \mathrm{~mA}$ direct current was achieved in $275 \mathrm{~nm}$ LEDs through enhanced light extraction efficiency (LEE) by using a transparent $\mathrm{AlGaN}: \mathrm{Mg}$ contact layer, a Rh mirror electrode, an AlN template on a patterned sapphire substrate, and encapsulation resin [8]. 


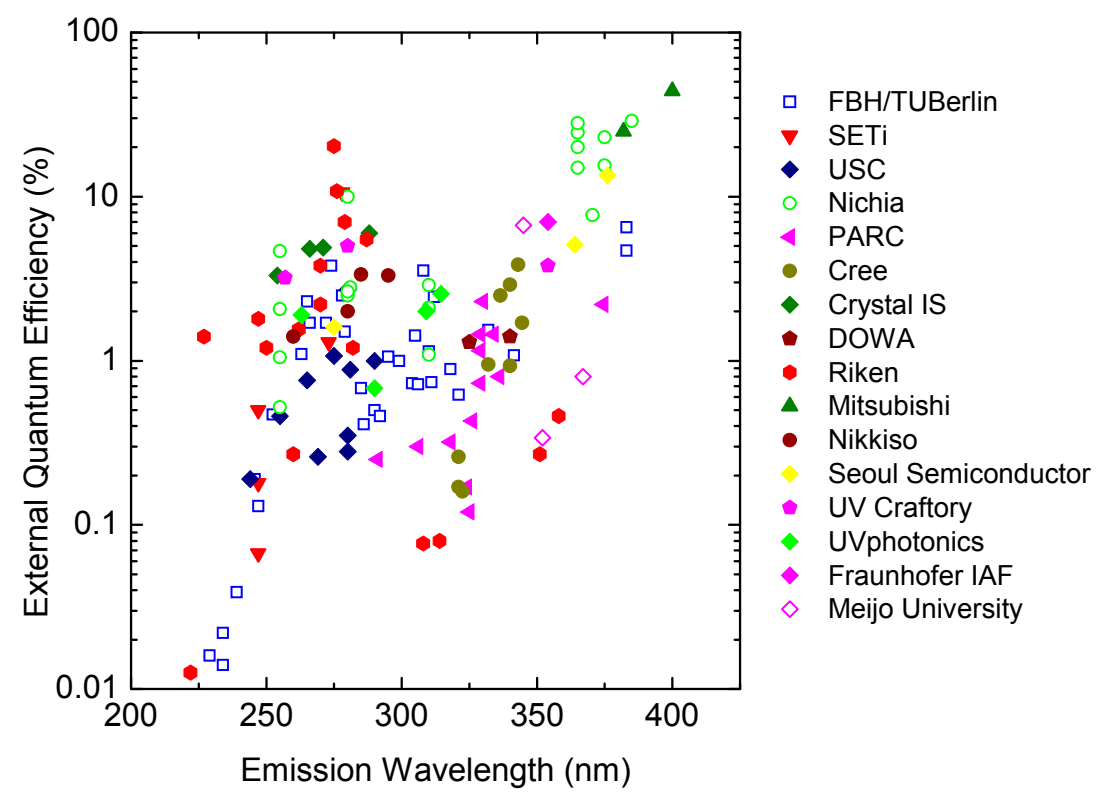

Figure 1. Reported external quantum efficiencies (EQE) for group III-nitrides-based near and deep ultraviolet (DUV) light-emitting diodes (LEDs) [1-18]. In part courtesy of Prof. M. Kneissl of Technische Universität Berlin.

As can be seen from Figure 1, despite the unquestionable progress exhibited of late, the EQE of DUV LEDs with emission wavelength below $350 \mathrm{~nm}$ is still much lower than those in the near UV range. There are multiple reasons responsible for the reduced performance of DUV devices, including:

(1) The unavailability of low-cost, lattice, thermal expansion coefficient-matched, and transparent substrate material. Bulk AlN single crystals are very expensive, while sapphire, the most commonly used substrate for DUV LEDs, has a large lattice mismatch $(13.3 \%)$ and large difference of thermal expansion coefficient with AlN $\left(7.5 \times 10^{-6} \mathrm{~K}^{-1}\right.$ for sapphire vs. $4.2 \times 10^{-6} \mathrm{~K}^{-1}$ for AlN), and inferior thermal conductivity.

(2) The low surface mobility of the Al species on the growth surface, which favors a high density of extended defects such as threading dislocations, resulting in low internal quantum efficiency (IQE) of DUV LEDs.

(3) The notorious low p-type conductivity in high Al-molar fraction AlGaN due to the large activation energy of $\mathrm{Mg}$ acceptor, which results in poor hole injection and also detrimental electron overflow from the active region.

(4) Low LEE caused by strong total internal reflection and self-absorption.

To conquer the above challenges, many approaches have been proposed and developed for growing better quality group III-nitride heterostructures. In the following, the approaches that have shown advantages/potential for enabling high-EQE DUV LEDs are discussed.

\section{Device Design for Improved Performance of Group III-Nitride DUV LEDs}

Before discussing challenges, current status, and prospective directions in materials development, we will first focus on the optimization of device design to improve carrier injection efficiency (CIE) and LEE for enhancing the performance of group III-nitride DUV LEDs. To achieve high CIE, an electron blocking layer (EBL) with sufficient high barrier height is required for the suppression of overflow electrons above the multiple quantum wells (MQWs) into the p-type layer. Hirayama et al. [19] reported that the use of a single layer AlGaN EBL with a very high Al-molar fraction of $95 \%$ or even $\mathrm{AlN}$ is still not sufficient to obtain the desired CIE. To overcome this, the design of AlGaN/AlGaN multiple 
quantum barriers (MQB) as EBL, which introduces multi-reflection effects, was proposed (see Figure 2). It was found that both the output power and the EQE were significantly increased when a single AlGaN EBL was replaced by the MQB. The EQE of a $250 \mathrm{~nm}$ LED was increased by approximately four times to $1.5 \%$ by implementing the MQB EBL design. It was estimated that the CIE of the $250 \mathrm{~nm}$ LED improved from about $20 \%$ to above $80 \%$ by using the MQB [20]. Similarly, $\mathrm{Al}_{x} \mathrm{Ga}_{1-\mathrm{x}} \mathrm{N} / \mathrm{Al}_{0.7} \mathrm{Ga}_{0.3} \mathrm{~N}$ electron blocking heterostructures (EBHs) were investigated to enhance the injection efficiency by Kolbe et al. [14] The output power of $290 \mathrm{~nm}$ LEDs with an optimized $\mathrm{AlN} / \mathrm{Al}_{0.7} \mathrm{Ga}_{0.3} \mathrm{~N}$ EBH increased by a factor of around 8.5 compared to LEDs with a conventional $\mathrm{Al}_{0.7} \mathrm{Ga}_{0.3} \mathrm{~N}$ EBL.

(a)

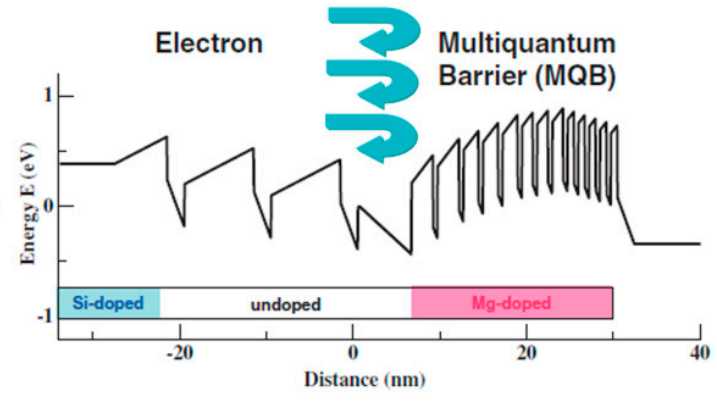

(b)

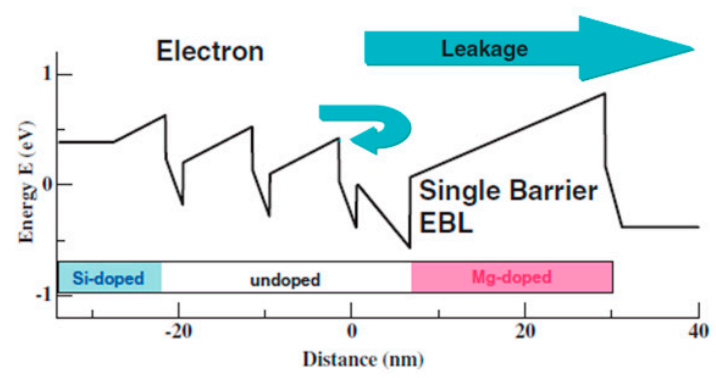

Figure 2. Schematic of electron injection into multiple quantum wells (MQWs) in AlGaN-based DUV LEDs using (a) a multiple quantum barrier (MQB) and (b) a single barrier electron blocking layer (EBL). Reprinted with permission from [17]. Copyright 2014, The Japan Society of Applied Physics.

DUV LEDs generally employ flip-chip configuration for efficient heat dissipation and light extraction [21-24]. In spite of this, flip-chip designs still suffer from a relatively low extraction efficiency caused by the dominant transverse magnetic (TM)-polarized light emission, which propagates mainly in the lateral direction [25]. Sidewall emission-enhanced (SEE) DUV LEDs with multiple light-emitting mesa stripes and three-dimensional reflectors between the stripes were explored to enhance the light extraction efficiency of TM-polarized light $[25,26]$. Remarkably enhanced light extraction with a strongly upward-directed emission due to the exposed sidewall of the active region and Al-coated selective-area-grown n-type GaN micro-reflectors was observed in the SEE DUV LEDs with an emission wavelength of $285 \mathrm{~nm}$. The devices also showed reduced operating voltage due to improved n-type ohmic contacts formed on the regrown n-GaN stripes compared with conventional LEDs.

A moth-eye structure was fabricated on the back side of the sapphire substrate for 255-280 nm UVC LEDs reported by Pernot et al., and on-wafer output power measurement revealed a 1.5-fold improvement of light extraction [1]. Ichikawa et al. [27] reported the application of hemispherical sapphire lenses bonded to the substrates of DUV LED chips to enhance the light extraction efficiency. The $255 \mathrm{~nm}$ DUV LEDs with a sapphire lens fabricated using the surface activated bonding method showed a light extraction efficiency enhancement of 2.8 times when compared to a reference LED lacking the lens, and an EQE of $4.56 \%$ was achieved. Inoue et al. $[5,24]$ developed large-area AIN nanophotonic structures to enhance the light extraction efficiency of DUV LEDs. The LEDs with the nanoimprinted AlN nanophotonic structures exhibited wider near-field emitting areas, stronger far-field extracted light intensities, and an approximately 20 -fold increase in the output power when 
compared with a conventional flat-surface DUV LED. A CW output power in excess of $150 \mathrm{~mW}$ for an injection current of $850 \mathrm{~mA}$ was achieved in the nanoimprinted UVC LEDs emitting at $265 \mathrm{~nm}$ [24].

Nagai et al. [28-30] investigated the feasibility of encapsulation of AlGaN-based DUV LEDs with silicone resin and with polymerized perfluoro-4-vinyloxy-1-butene (BVE)-based fluorine polymers having $-\mathrm{COOCH}_{3}$ ends in comparison with fluorine polymers having terminal ends of $-\mathrm{CF}_{3}$ and $-\mathrm{COOH}$ in order to enhance light extraction. Serious damage to the electrode metal was observed, except for the BVE-based polymer with $-\mathrm{CF}_{3}$ ends. For DUV LEDs encapsulated with the selected BVE-based polymers with $-\mathrm{CF}_{3}$ ends, a stable 1.5 times light extraction enhancement with no degradation of the fluorine resin over $6000 \mathrm{~h}$ at a wavelength of $265 \mathrm{~nm}$ was obtained. In addition, a $3 \times 4$ array module of encapsulated 285 LED dies on a simple AlN submount with an output power of $472 \mathrm{~mW}$ at $200 \mathrm{~mA}$ and $63 \mathrm{~V}$ was achieved with a 1.5 fold light extraction enhancement as well.

\section{Growth and Optical Properties of Bulk AlN for DUV LEDs}

Ideal substrates for the growth of AlGaN-based DUV LEDs must possess the physical properties that closely match with the epilayers being grown on them. The requirements include favorable crystal structure (similar symmetry, closely matched lattice constants), similar thermal expansion coefficient, high thermal conductivity, and optical transparency. Table 1 lists the major characteristics of substrates applicable for DUV LEDs. None of the typically used substrates is ideal and fully satisfies all the requirements. Because of silicon's low cost, large wafer size, high crystalline quality, good electrical conductivity, and feasibility of its removal through chemical etching to allow back light extraction, III-nitride based LEDs grown on silicon substrates have also been extensively studied. However, large lattice and thermal mismatch between III-nitrides and silicon result in tensile strain, leading to high crack and dislocation densities in DUV LED structures. Both 6H-Silicon carbide (SiC) and $4 \mathrm{H}-\mathrm{SiC}$ exhibit much smaller lattice and thermal misfits with III-nitrides. They also have the advantages of good chemical stability, and high electrical and thermal conductivity, but relatively high cost compared with sapphire and silicon substrates. GaN substrates have a low lattice mismatch with the AlGaN-based heterostructures grown on them (between $0 \%$ and $2.4 \%$, depending on Al-molar fraction) and excellent physical properties such as high thermal conductivity and mechanical strength. The main growth methods for bulk GaN, or bulk-like GaN, include hydride vapor phase epitaxy (HVPE) and ammonothermal growth. So far, GaN crystals with diameters from 2 to 4 inch and dislocation densities below $10^{5} \mathrm{~cm}^{-2}$, which is much lower than that in GaN grown on foreign substrates, have been reported for both methods [31,32]. However, for DUV LEDs, GaN has the drawbacks of generation of tensile strain in the AlGaN epilayers with high Al-molar fraction and light absorption and also high-cost. For $\mathrm{Si}, \mathrm{SiC}$, and $\mathrm{GaN}$ substrates, when and if used, the substrates must be selectively removed during fabrication for DUV LEDs which are back-emitting. Owing to its excellent DUV transparency, low cost and similar crystal symmetry as III-nitrides, today's efforts in development of DUV LEDs are mainly focused on utilization of sapphire as the substrate despite its shortcomings. Typical threading dislocation density (TDD) of AlGaN heterostructures on sapphire conventionally produced using low-temperature AlN buffer is above $10^{10} \mathrm{~cm}^{-2}$ due to the large lattice- and thermal-mismatch between AlGaN and sapphire. This is detrimental in that a relatively high IQE of DUV LEDs (above 50\%) requires TDD values below $10^{9} \mathrm{~cm}^{-2}$ [13]. We 1 leave the discussion of the approaches employed for reducing TDD in AlGaN heterostructures on foreign substrates to Sections 5-7. In the remainder of this section we focus on the progress made in bulk growth and properties of AlN, which is the most promising substrates for DUV LEDs due to its low lattice mismatch for high Al-molar fraction AlGaN, high breakdown voltage and thermal conductivity, chemical inertness, despite the restrictions imposed by its limited availability, and high cost at the time of this writing. 
Table 1. Lattice parameters and properties of substrate materials for growth of deep ultraviolet light-emitting diodes (DUV LEDs) [33,34]. Mismatch calculations for sapphire take into account the 30 degree in-plane rotation.

\begin{tabular}{|c|c|c|c|c|c|c|c|c|}
\hline Substrate & $\begin{array}{l}\text { a-Axis } \\
(\AA)\end{array}$ & c-Axis Å & $\begin{array}{l}\text { Mismatch } \\
\text { to GaN }\end{array}$ & $\begin{array}{l}\text { Mismatch } \\
\text { to AlN }\end{array}$ & $\begin{array}{l}\text { Thermal } \\
\text { conductivity } \\
\text { (W/cm K) }\end{array}$ & $\begin{array}{c}\text { UV } \\
\text { transparency }\end{array}$ & Availability & Price \\
\hline Sapphire & 4.765 & 12.982 & $16.1 \%$ & $13.3 \%$ & 0.23 & $\sqrt{ } \sqrt{ }$ & $\sqrt{ } \sqrt{ }$ & $\sqrt{ } \sqrt{ }$ \\
\hline Si (111) & 3.840 & 3.136 & $17 \%$ & $19 \%$ & 1.6 & $x$ & $\sqrt{ } \sqrt{ }$ & $\sqrt{ } \sqrt{ }$ \\
\hline $6 \mathrm{H}-\mathrm{SiC}$ & 3.073 & 15.117 & $3.8 \%$ & $1.3 \%$ & 4.9 & $x$ & $\sqrt{ }$ & $x$ \\
\hline $4 \mathrm{H}-\mathrm{SiC}$ & 3.076 & 10.053 & $3.7 \%$ & $1.2 \%$ & 3.7 & $\mathrm{X}$ & $\sqrt{ }$ & $X$ \\
\hline GaN & 3.189 & 5.186 & $0 \%$ & $2.4 \%$ & 3.2 & $x$ & $\mathrm{X}$ & $X X$ \\
\hline $\mathrm{AlN}$ & 3.112 & 4.982 & $2.5 \%$ & $0 \%$ & 2.1 & $\sqrt{ }$ & $x x$ & $X X X$ \\
\hline
\end{tabular}

The most promising technique for the growth of bulk AlN crystals is sublimation-recondensation, also known as the physical vapor transport (PVT) method [35]. The sublimation-recondensation reaction can be written as

$$
2 \mathrm{AlN}(\mathrm{s}) \leftrightarrow 2 \mathrm{Al}(\mathrm{g})+\mathrm{N}_{2}(\mathrm{~g})
$$

In the growth reactor, AlN powder source is sublimated from a crucible with a temperature above $2000{ }^{\circ} \mathrm{C}$ under $\mathrm{N}_{2}$ atmosphere. Due to the thermal gradient with an intentionally induced slightly higher source temperature compared to the seed temperature, $\mathrm{Al}$ and $\mathrm{N}$ atoms transport toward the seed and condense to form an AlN bulk crystal. Although PVT growth of AlN can take place at temperatures below $1800^{\circ} \mathrm{C}$, the material quality is limited by the mobility and reactivity of the atoms; therefore, higher temperatures, around $2200^{\circ} \mathrm{C}$, are more favorable for enhancing both the growth rate and crystal quality. Typically, bulk AlN crystals are grown at temperatures between $1800{ }^{\circ} \mathrm{C}$ and $2200{ }^{\circ} \mathrm{C}$, a reactor pressure in the range of $300-900 \mathrm{mbar}$, and a thermal gradient of $10-50 \mathrm{~K} / \mathrm{cm}$, which yield a growth rate around several hundred micrometers per hour. In addition to the precise control of both the seed and source temperature and the purity of the source, the choice of the crucible material is also crucial to the quality and the properties of the resulting AlN crystals [36].

Although there are still challenges, such as contamination from impurities, lack of large-sized AlN seeds, and difficulty in tailoring desired thermal profile inside the growth reactor that hinder reproducible growth to cite a few [37], several groups have achieved PVT-grown AlN single crystals with diameters up to 2 inch [35,38-42]. X-ray rocking curves with a full width at half maximum (FWHM) close to 30 arcsec for both (0002) and (1012) reflections and etch pit densities (EPDs) below $10^{4} \mathrm{~cm}^{-2}$ were reported with an usable area of $~ 85 \%$ [35]. Low dislocation density AlGaN epilayers with both symmetric and asymmetric rocking curves below 100 arcsec have been grown on these AlN wafers. Significant improvements in the performances of DUV LEDs have also been demonstrated by the use of PVT-AlN substrates [2,43-45]. For instance, an IQE of $80 \%$ was reported for AlGaN multiple quantum wells with emission wavelength of $258 \mathrm{~nm}$ grown on PVT-AlN substrates, achieved with the reduction of point defects by growth optimization [46].

In addition to crystal quality and size, UV transparency of the AlN substrate is also of crucial importance for applications in DUV LEDs. Although AlN should be transparent down to $210 \mathrm{~nm}$ due to its wide bandgap of $6 \mathrm{eV}$, PVT-AlN substrates have shown wide optical absorption bands below the band gap in the blue and UV ranges $[38,47,48]$. These absorption bands are attributed to residual impurities such as silicon, oxygen (mainly from the source materials), and carbon (mainly from the reactor parts such as $\mathrm{TaC}$ crucible) and intrinsic point defects, and $\mathrm{Al}$ vacancies. The underlying mechanisms for the formation of these bands are still under discussion [38,42,47-53].

Specifically, at least three absorption bands at $2.8 \mathrm{eV}, 3.3-4.3 \mathrm{eV}$, and $4.7 \mathrm{eV}$ were found and discussed for PVT-grown AlN. The origin of the $2.8 \mathrm{eV}$ band is still an issue of intense debate. Some researcher ascribed it to transition between the valence band and $\mathrm{Al}$ vacancy $\left(\mathrm{V}_{\mathrm{Al}}\right)$ level [53]. However, others attributed it to transitions between oxygen on $\mathrm{N}$ sites $\left(\mathrm{O}_{\mathrm{N}}\right)$ and $\mathrm{V}_{\mathrm{Al}}\left(\mathrm{O}_{\mathrm{N}}-\mathrm{V}_{\mathrm{Al}}\right)$ [47]. The broad 3.3 $-4.3 \mathrm{eV}$ band is presumably associated with $\mathrm{V}_{\mathrm{Al}}$ and/or oxygen related complexes, and reduction 
of oxygen contamination in the source material was found to lead to a significant decrease of UV absorption in both colorless and yellowish areas of bulk AlN [47]. The $4.7 \mathrm{eV}$ band with an absorption coefficient above $1000 \mathrm{~cm}^{-1}$, which is detrimental to DUV LEDs with emission wavelength shorter than $270 \mathrm{~nm}$, was typically observed in crystals grown with TaC crucibles. To minimize this absorption, the AlN substrates were thinned down to $20 \mu \mathrm{m}$ [3]. The origin of the $4.7 \mathrm{eV}$ band was reportedly related to carbon contaminations [51]. Density functional theory (DFT) calculations have predicted that substitutional carbon on the nitrogen site $\left(C_{N}\right)$ introduces absorption at this energy. Optical absorption measurements performed on a series of single crystalline AlN wafers with different carbon concentrations showed that the absorption coefficient at $4.7 \mathrm{eV}$ linearly increased with carbon content, supporting the prediction of $\mathrm{C}_{\mathrm{N}}$ being responsible for the said absorption [51].

Another promising method for growing bulk AlN crystals is hydride vapor phase epitaxy (HVPE). Compared to the PVT produced AlN, HVPE grown AlN has much better transparency in the DUV range due to better controlled carbon incorporation. Freestanding AlN substrates prepared by HVPE also showed a steep optical transmission cutoff near the band edge [54]. The disadvantage of the HVPE method is that, it may produce AIN crystals with high TDD and crack densities due to the large lattice and thermal mismatch between AlN and the foreign substrates such as SiC and sapphire, as shown in Table 1. Typical TDD in HVPE AlN on foreign substrates is above $10^{7} \mathrm{~cm}^{-2}$. For example, a TDD of $1.5 \times 10^{8} \mathrm{~cm}^{-2}$ on sapphire [54] and $3 \times 10^{9} \mathrm{~cm}^{-2}$ on Si (111) [55] were reported.

To avoid cracks and reduce TDD, HVPE growth of AlN using native PVT-AlN substrates has been explored. Although AlN layers grown by low-pressure HVPE on on-axis PVT-AlN (0001) substrates were reported to echibit cracks due to tensile strain, no cracks were found in the structures grown on AlN (0001) substrates with $5^{\circ}$ off-cut angle [56]. X-ray $\omega$-rocking curves with FWHM values of 277 and 306 arcsec were achieved for the (0002) and (1010) reflections. It was also found that the $\mathrm{Si}$ and $\mathrm{C}$ impurity concentrations in the overgrown AlN layer reduced to half of those in the PVT-AlN substrates. In another study [57], FWHM values as small as 31 and 32 arcsec were reported for the (0002) and (1011) reflections of $\omega$-rocking curves, respectively, for $114 \mu \mathrm{m}$-thick HVPE-AIN, grown on a bulk PVT-AlN substrate. The HVPE-AlN has larger external optical transmittance in the DUV range compared to the PVT-AlN substrate, with a steep optical transmission cutoff at $206.5 \mathrm{~nm}$ (Figure 3), which was attributed to lower concentrations of carbon, and oxygen impurities, and $\mathrm{V}_{\mathrm{Al}}$ in the HVPE-AlN substrate.

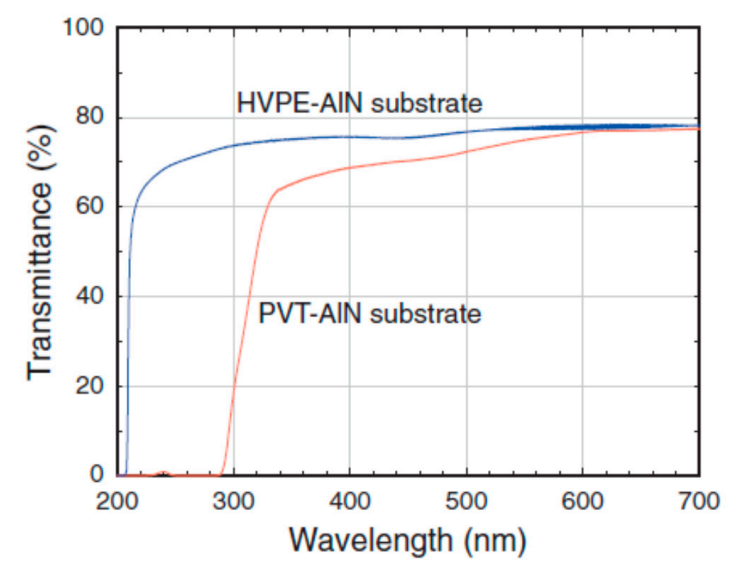

Figure 3. External optical transmission spectra of physical vapor transport (PVT)- and hydride vapor phase epitaxy (HVPE)-AlN substrates measured at RT in air. Substrates of the same thickness and surface polish state were used. Reprinted with permission from [57]. Copyright 2012, The Japan Society of Applied Physics.

By using HVPE-AlN as a substrate for growth and subsequent removal of it by mechanical polish, an output power of $28 \mathrm{~mW}$ and an EQE of $2.4 \%$ were obtained at an injection current of $250 \mathrm{~mA}$ 
in $268 \mathrm{~nm}$ DUV LEDs [58]. In another study, TDD in $261 \mathrm{~nm}$ DUV LED heterostructures (except the p-GaN layer) grown on HVPE-AlN/PVT-AlN substrates was found to be below $10^{6} \mathrm{~cm}^{-2}$ from transmission electron microscopy (TEM) analysis. The lifetime of these LEDs was estimated to be over $10,000 \mathrm{~h}$ for CW operation at $50 \mathrm{~mA}$, and over $5000 \mathrm{~h}$ for $\mathrm{CW}$ operation at $150 \mathrm{~mA}$ [9].

\section{High-Temperature Growth of AlN and High Al-Molar Fraction AlGaN by MOCVD}

Not only the lattice and thermal mismatch between the epilayer and foreign substrates, but also the low surface adatom mobility of $\mathrm{Al}$ at typical growth temperatures (below $1200{ }^{\circ} \mathrm{C}$ ) is a dominating factor that leads to the generation of high TDD in AlGaN-based DUV LEDs. Due to the lower surface migration rate (mobility) of $\mathrm{Al}$ than that of $\mathrm{Ga}$, it is more difficult to achieve the layer-by-layer two-dimensional growth of AlN and high Al-molar fraction AlGaN. At typical growth temperatures $\left(1200{ }^{\circ} \mathrm{C}\right.$ or less), $\mathrm{Al}$ adatoms cannot move to energetically favorable lattice steps, thus resulting in three-dimensional (3D) islandic growth and the formation of extended defects such as dislocations and grain boundaries. Therefore, the crystalline quality degrades in $\mathrm{AlGaN}$ with increasing $\mathrm{Al}$ content. Because the surface diffusion coefficient is strongly temperature dependent, and adatom surface mobility increases with increasing growth temperature, high-temperature MOCVD technique has been employed for the growth of AlN and high Al-molar fraction AlGaN.

Figure 4 shows the evolution of surface morphologies of AlN on sapphire substrate grown at different temperatures [59]. When growing AlN at growth temperatures typical of $\mathrm{GaN}\left(\sim 120{ }^{\circ} \mathrm{C}\right)$ the surface showed 3D columnar-like morphology (not shown). At an increased temperature of $1300{ }^{\circ} \mathrm{C}$, transition from the rough morphology to a rather flat surface exhibiting a high density of hexagonal pits was observed. When the temperature was raised further up to $1500{ }^{\circ} \mathrm{C}$, the pit density reduced drastically and a smooth surface with an rms roughness value of $0.4 \mathrm{~nm}$ was achieved.
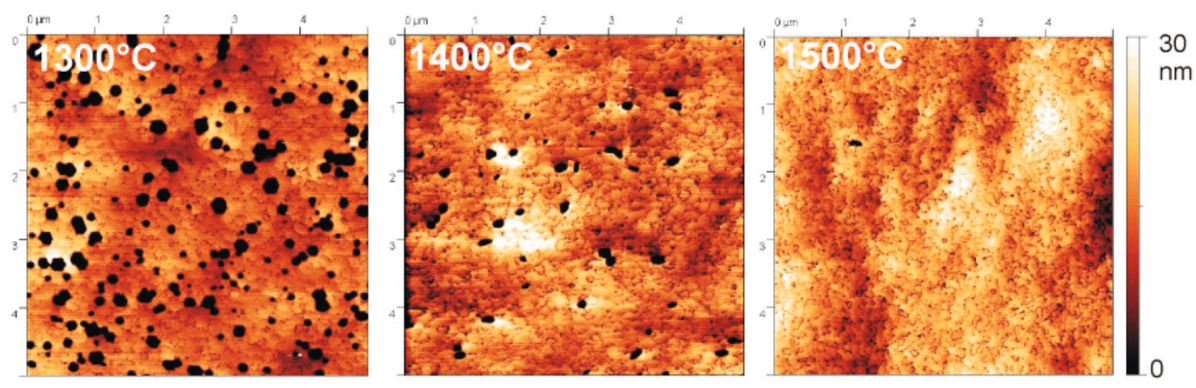

Figure 4. Atomic force microscopy (AFM) scans $(5 \times 5 \mu \mathrm{m})$ of $0.7 \mu \mathrm{m}$ thick AlN: nid on sapphire grown at temperatures of $130{ }^{\circ} \mathrm{C}, 1400{ }^{\circ} \mathrm{C}$, and $1500^{\circ} \mathrm{C}$. RMS values are $4 \mathrm{~nm}, 1 \mathrm{~nm}$ and $0.4 \mathrm{~nm}$ from left to right. Reprinted with permission from [59]. Copyright 2008, WILEY-VCH Verlag GmbH \& Co. KGaA, Weinheim.

In addition to the reduction of TDD and providing a flat surface morphology, high temperature growth was also found to be effective for reducing the density of unintentional impurities and point defects in AlN and high Al-molar fraction AlGaN, which is critically important for enhancing the IQE of DUV LEDs. Secondary ion mass spectroscopy (SIMS) has shown that, in pit-free AlN layers grown at $1500{ }^{\circ} \mathrm{C}$ and above, oxygen and Si concentrations were $5 \times 10^{17} \mathrm{~cm}^{-3}$ and $1 \times 10^{17} \mathrm{~cm}^{-3}$, respectively, while oxygen concentration was above $1 \times 10^{19} \mathrm{~cm}^{-3}$ in samples with a high pit density [59]. Similar results have been reported in another study [60,61]. In AlN films grown at high temperatures (above $1350{ }^{\circ} \mathrm{C}$ ), they were found to be below the detection limit of SIMS, while for AlN grown below $1200^{\circ} \mathrm{C}$, the $\mathrm{Si}, \mathrm{C}$, and $\mathrm{O}$ concentrations were of the order of $10^{18}-10^{19} \mathrm{~cm}^{-3}$. The low temperature $(12 \mathrm{~K})$ cathodoluminescence $(\mathrm{CL})$ spectra recorded on high temperature grown AlN films were characterized by sharp excitonic emission peaks with weak broad defect-band emission [62]. In contrast, the CL spectra from samples grown at relatively low temperatures revealed intense defect-band emission with broad near band edge emission. Time-resolved photoluminescence (TRPL) and time-resolved 
cathodoluminescence (TRCL) measurements for high Al-molar fraction AlGaN films also confirmed that high temperature growth with appropriate defect management is preferable to reduce nonradiative recombination, which is crucial for high IQE in DUV LEDs [61].

\section{Pulsed-Flow Growth of AlN and High Al-Molar Fraction AlGaN}

To make high-temperature growth feasible, specific modifications of MOCVD reactor hardware, including TaC-coated susceptor, BN reactor parts, and actively cooled stainless-steel gas inlets are required [59]. In order to obtain AlN and high Al-molar fraction AlGaN with high crystalline quality and flat surface morphology by using moderate growth temperatures, pulsed-flow growth methods, which can effectively promote the surface migration of $\mathrm{Al}$ (and Ga and In) adatoms, have been developed instead of the conventional continuous growth. There are at least three types of pulsed-flow growth methods, namely (a) $\mathrm{NH}_{3}$ pulse-flow growth $[17,63,64]$, (b) pulsed atomic layer epitaxy (PALE) [65,66], and (c) migration-enhanced metalorganic chemical vapor deposition (MEMOCVD) [67-69], as shown schematically in Figure 5.

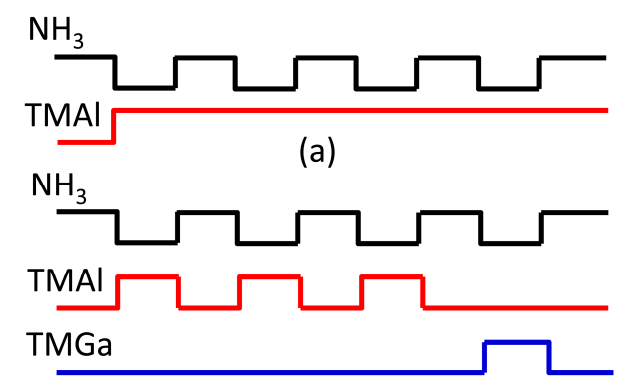

(b)

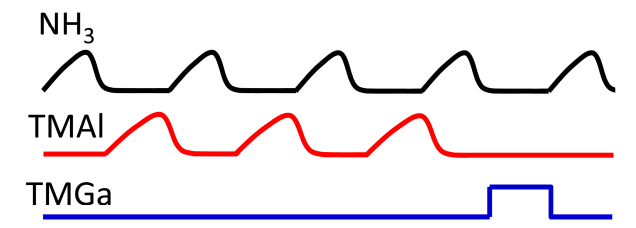

(c)

Figure 5. Representative gas flow sequences for (a) AlN growth by $\mathrm{NH}_{3}$ pulse-flow method, $\mathrm{AlGaN}$ growth by (b) pulsed atomic layer epitaxy (PALE) and (c) migration-enhanced metal organic chemical vapor deposition (MEMOCVD) methods. Patterned after Reference [17,65,69].

For the $\mathrm{NH}_{3}$ pulse-flow growth of $\mathrm{AlN}$, pulsed $\mathrm{NH}_{3}$ flow was employed to enhance the lateral migration of $\mathrm{Al}$ adatoms, while TMAl flow was kept constant during the $\mathrm{NH} 3$ pulsed-flow sequence to ensure Al-rich growth conditions [64]. This is thought to be necessary for suppressing polarity inversion from $\mathrm{Al}$ to $\mathrm{N}$. In order to reduce the surface roughness, continuous flow mode with high growth rate was introduced between the $\mathrm{NH}_{3}$ pulse-flow mode growth segments. By employing periodic pulsed- and continuous-flow modes, low TDD AIN layers with atomically flat surface were achieved on sapphire and Si substrates. The edge and screw-type dislocation densities in AlGaN buffer layers on AlN grown by the $\mathrm{NH}_{3}$ pulsed-flow multilayer growth technique were reported to be $7.5 \times 10^{8}$ and $3.8 \times 10^{7} \mathrm{~cm}^{-2}$, respectively [70].

Different from the $\mathrm{NH}_{3}$ pulse-flow growth, both group III and group $\mathrm{V}$ precursors are sequentially modulated in the PALE method, wherein the $\mathrm{NH}_{3}$ pulse always follows the metalorganic pulses. Reduced parasitic pre-reactions and enhanced surface migration of $\mathrm{Al}$ adatoms, afforded by the PALE technique, promote lateral growth of AlN. FWHM values of the (0002) and (112̄4) reflections of XRD $\omega$-rocking curve were reported to be less than 60 arcsec and 250 arcsec, respectively, in AlN epilayers grown at a temperature of $1070{ }^{\circ} \mathrm{C}$ [71]. The PALE approach has also been adopted for growth of high Al-molar fraction AlGaN ternary and AlInGaN quaternary layers and MQWs with very short emission 
wavelength (below $230 \mathrm{~nm}$ ). This method allows accurate control of the quaternary layer composition and thickness by simply changing the number of aluminum, indium, and gallium pulses in a unit cell and the number of unit cell repeats $[65,66]$.

MEMOCVD is carried out at relatively high temperatures $\left(>1200^{\circ} \mathrm{C}\right)$ and low reactor pressure conditions $(<100$ Torr). In contrast to PALE, the duration and waveforms of precursor pulses in MEMOCVD can be partially overlapped, allowing for a continuum of growth technique ranging from atomic layer epitaxy to conventional MOCVD. By employing MEMOCVD, a high growth rate for buffer layers and slower growth rate for active layers with reduced growth temperature and substantially improved quality can be achieved [72]. Crack-free 5- to 10- $\mu \mathrm{m}$-thick high-quality AlN on sapphire with TDD of $2 \times 10^{8} \mathrm{~cm}^{-2}$ for all dislocation types has been grown by HT-MEMOCVD. Moreover, HT-MEMOCVD growth yielded atomically a flat surface with RMS roughness of $0.8 \AA$ as measured by atomic force microscopy (AFM), similar to that achieved for homoepitaxial AlN on native AlN bulk substrates [69]. Combined with improved device design, MEMOCVD growth produced $278 \mathrm{~nm}$ AlGaN-based DUV LEDs on sapphire substrates with a maximum EQE of $10.4 \%$ at $20 \mathrm{~mA} C W$ current and output powers up to $9.3 \mathrm{~mW}$ [4].

\section{Epitaxial Lateral Overgrowth of AlN and High Al-Molar Fraction AlGaN}

The epitaxial lateral overgrowth (ELO) technique has proven to be a useful approach for growing epilayers with low TDD on foreign substrates. It provides an avenue for DUV-LEDs with improved performance. The method relies on the growth of nitrides on windows opened in a dielectric mask material such as $\mathrm{SiO}_{2}$ or patterned substrate/template formed by etching followed by lateral extension and coalescence [73,74]. The defects can propagate to the upper layer only through the areas where there are windows, while the defect density is considerably reduced in the laterally grown area. Growth anisotropy in the form of different growth rates on different crystallographic planes plays a key role in this method [75]. One must also be concerned with defects caused by joining of advancing wings over the masked areas [76].

Due to its selectivity, the regrowth of GaN and low Al-molar fraction AlGaN commences only on the mask-free window area with no nucleation on the masked areas by the dielectric. Therefore, dielectric mask material produced by ex situ deposition and etching procedures [77] or in situ spontaneous etching [78] can be used for ELO GaN and low Al-molar fraction AlGaN. Figure 6 shows a cross-sectional transmission electron microscopy (TEM) image of an ELO GaN sample on sapphire substrate with in-situ nanoporous $\mathrm{SiN}_{\mathrm{x}}$ mask [79]. Most threading dislocations are blocked by the $\mathrm{SiN}_{\mathrm{x}}$ network, and those emanating from the pores are mostly bent into horizontal configurations.

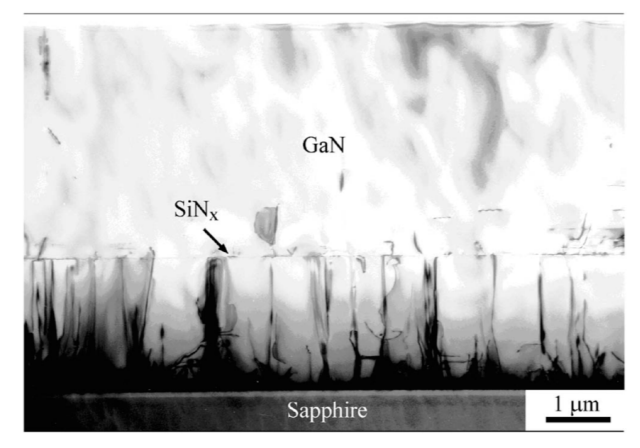

Figure 6. Cross-sectional transmission electron microscopy (TEM) micrograph of a GaN thin film grown with $5 \mathrm{~min}$ in situ $\mathrm{SiN}_{\mathrm{x}}$ network by MOCVD on sapphire. Reprinted from [79], with the permission of AIP publishing.

The ELO technique with dielectric masks has also been used for TDD reduction in AlGaN with low Al-molar fraction intended for applications in LEDs in the UVA range [80]. For AlN and high Al-molar fraction $\mathrm{AlGaN}$, the slow lateral growth rate of $\mathrm{Al}$ containing compounds and the low-selectivity 
between a mask and unmasked area due to large sticking coefficient of $\mathrm{Al}$ adatoms precludes the possibility of using dielectric masks for ELO. Maskless ELO by laterally overgrowing a trench instead of a mask material is an alternative avenue to reduce densities of both threading dislocations and cracks. ELO of AlN and high Al-molar fraction $\mathrm{AlGaN}$ such as $\mathrm{Al}_{0.96} \mathrm{Ga}_{0.04} \mathrm{~N}$ on sapphire or $\mathrm{SiC}$ substrate have been reported by several groups [76,81-83]. Significant reduction in TDD was observed in the areas between ridges. A maximum output power of $2.7 \mathrm{~mW}$ under $\mathrm{CW}$ operation of $273 \mathrm{~nm}$ DUV LEDs on ELO AIN templates with the wing region having TDD of $3 \times 10^{8} \mathrm{~cm}^{-2}$ was reported by Hirayama et al. [84] By reducing the TDD in AlN layers on sapphire from $10^{10} \mathrm{~cm}^{-2}$ to $10^{9} \mathrm{~cm}^{-2}$, output powers of $1 \mathrm{~mW}$ and about $4 \mathrm{~mW}$ for $295 \mathrm{~nm}$ and $324 \mathrm{~nm}$ LEDs, respectively, were demonstrated by Kueller et al. [73] This method has also been applied for growing AlN template on Si (111) substrate, as illustrated in Figure 7. ELO AlN templates on Si (111) substrate with FWHM values of 920 and 780 arcsec for XRD $\omega$-rocking curves from the (0002) and (1011) reflections, respectively, with simultaneous reduction in crack density were achieved by Zhang et al. [85] A peak pulsed power and slope efficiency of $\sim 0.6 \mathrm{~mW}$ and $\sim 1.3 \mathrm{~mW} / \mathrm{mA}$, respectively, were demonstrated for $359 \mathrm{~nm}$ UV LEDs after removing the $\mathrm{Si}$ (111) substrate. In another report, FWHMs of 780 and 980 arcsec for XRD $\omega$-rocking curves from the (0002) and (1012) reflections, respectively, were achieved in ELO AlN on Si (111). DUV LEDs with an emission wavelength of $256-278 \mathrm{~nm}$ exhibiting an output power of $\sim 10 \mu \mathrm{W}$ at a DC injection current of $140 \mathrm{~mA}$ without removing the Si substrate [86].

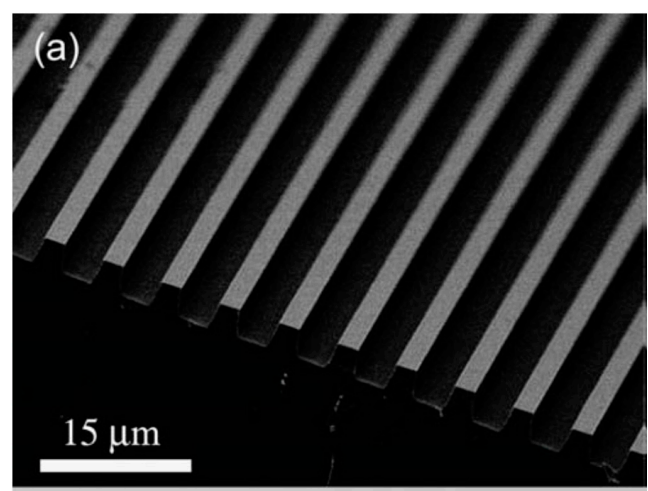

(b)

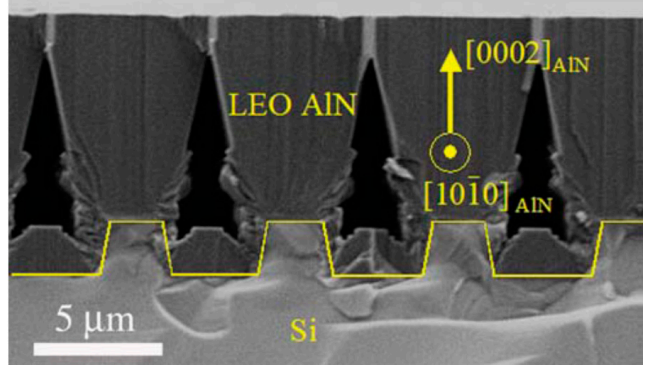

Figure 7. Scanning electron microscope (SEM) images of (a) perspective view of the stripe-patterned AlN/Si(111) template with nominally $3 \mu \mathrm{m}$ ridges and $3 \mu \mathrm{m}$ trenches $(6 \mu \mathrm{m}$ period) and (b) cross-sectional view of the ELO AlN layer on the patterned template. The patterning stripe is along [10110] AlN. Reprinted from [85], with the permission of AIP publishing.

\section{Pseudomorphic Growth of High Al-Molar Fraction AlGaN on AlN}

Bulk AlN single crystal substrates or AlN templates with low TDD by using the abovementioned approaches offer the opportunity to grow high quality DUV LED heterostructures. However, growing lattice-matched $\mathrm{AlGaN}$ layer exceeding the critical thickness on $\mathrm{AlN}$, results in the generation of new dislocations due to the lattice mismatch. To avoid this, pseudomorphic growth of high Al-molar 
fraction, AlGaN with compressive strain on AlN has been developed $[58,87,88]$. Because almost no new defects are generated in the pseudomorphic region, the crystalline quality of the AlGaN-based heterostructures becomes comparable to the starting substrate.

If one assumes that the Matthews and Blakeslee model is applicable, the critical thickness for AlGaN layer with an Al molar fraction of 0.6 on AlN is estimated to be only about $40 \mathrm{~nm}$, which is impractically small for use in DUV LEDs. Fortunately, researchers found that, by using a transitional layer, which consisted of a linearly graded alloy with composition changed from AlN to the desired Al-molar fraction, it is possible to grow pseudomorphic AlGaN with a thickness ranging from several hundreds of nanometers to more than a micrometer, depending on the Al-molar fraction [87]. Generally, sufficiently thick pseudomorphic AlGaN layers with $\mathrm{Al}$ content above 70\% can be grown on $\mathrm{AlN}$ for use in DUV LEDs with wavelengths below $280 \mathrm{~nm}$, while layers with lower Al content tend to relax due to lattice mismatch. Fully pseudomorphic $500 \mathrm{~nm}$ thick AlGaN layers with Al content of $60 \%$ and $1 \mu \mathrm{m}$ thick nearly pseudomorphic layers with $\mathrm{Al}$ content of $70 \%$ have been demonstrated [87]. The advantage of pseudomorphic growth was confirmed by XRD rocking curve measurements. For a $600 \mathrm{~nm}$ thick pseudomorphic $\mathrm{Al}_{0.72} \mathrm{Ga}_{0.28} \mathrm{~N}$ layer, the FWHM values of the (0002) and (1012) reflections were 81 and 104 arcsec, respectively, compared to 64 and 89 arcsec in AlN [87]. By contrast, FWHM values of the (0002) and (1012) reflections increased from 49 and 30 arcsec, respectively, in AlN to 239 and 302 arcsec in a $500 \mathrm{~nm}$ thick relaxed $\mathrm{Al}_{0.50} \mathrm{Ga}_{0.50} \mathrm{~N}$ sample.

Pseudomorphic growth has been also found to effectively improve the light extraction efficiency by switching the polarization of the emitting light. It is known that the opposite sign of the crystal field splitting energy in GaN (12.3 meV) vs. AlN (-221 meV) [34] results in the switching of the light polarization from TE in GaN to TM in AlN. The latter holds for high Al-molar fractions used to generate shorter emission wavelengths. The extraction efficiency of TM-polarized light is one order of magnitude lower than that of TE-polarized light, which is one of the critical factors that limit the EQE of AlGaN-based DUV LEDs. Several studies showed that the light generated using AlGaN-based heterostructures switches its polarization from TE to TM mode for Al-molar fractions anywhere between $20 \%$ and $40 \%$ [89,90]. Recently, Sharma et al. demonstrated theoretically that the critical Al-molar fraction at which the polarization switches depends on the amount of residual strain in the AlGaN layer [91]. In pseudomorphically grown AlGaN, the critical Al-molar fraction for polarization switching can be as high as $80 \%$. Figure 8 shows the degree of polarization of emission from LEDs fabricated on sapphire or AlN substrates [92]. The tendency for the polarization of the emitted light to switch from TE polarization to TM polarization with decreasing wavelength is clearly seen in the figure. However, Device 1 pseudomorphically grown on AlN substrate emits highly TE-polarized light with a wavelength of $253 \mathrm{~nm}$. According to theoretical computations [92], the switch of polarization from TE to TM depends on the strain in the quantum well. For an active region that is pseudomorphic to bulk AlN, $\mathrm{a}_{\mathrm{QW}}$ - $\mathrm{a}_{\text {bulk-AlN }}=0$, and the expected polarization is TE, which is the case of Device 1 . For Devices 2-4 grown on sapphire, it was proposed that the strain state of the active regions corresponds to $\mathrm{a}_{\mathrm{QW}}$ - $\mathrm{a}_{\text {bulk-AlN }}>0.01 \AA$. The compressive strain in the active region of these devices is less than that required for TE polarization; therefore, showing strong TM-polarized emission. Reich et al. [93] demonstrated that, by using narrow QWs and high Al content barrier on compressively strained ELO AlN/sapphire templates, strongly TE-polarized emission was achieved for pseudomorphic DUV LEDs with emission wavelength as short as $239 \mathrm{~nm}$.

Improvement of device performance through pseudomorphic growth has also been demonstrated by several groups $[3,10,88]$. A high IQE value of $\sim 80 \%$ at a photo-generated carrier density of $10^{18} \mathrm{~cm}^{-3}$ was achieved in UVC MQW structures emitting at $\sim 258 \mathrm{~nm}$, which were pseudomorphically grown on bulk AlN substrates that contain less than $10^{3} \mathrm{~cm}^{-2}$ dislocations [46], as revealed by synchrotron white-beam X-ray topography [94]. In an encapsulated pseudomorphic LED structure with improved LEE, through thinned AlN substrate, an output power of over $60 \mathrm{~mW}$ and an EQE of $4.9 \%$ were realized in continuous wave operation [3]. Pseudomorphic LEDs also show improved lifetimes and reliability. LEDs of $266 \mathrm{~nm}$ tested, in both surface mount design and TO-39 package, showed lifetimes 
above $1000 \mathrm{~h}$ under a variety of case temperatures and currents using performance degradation of $50 \%$ as the marker [10].

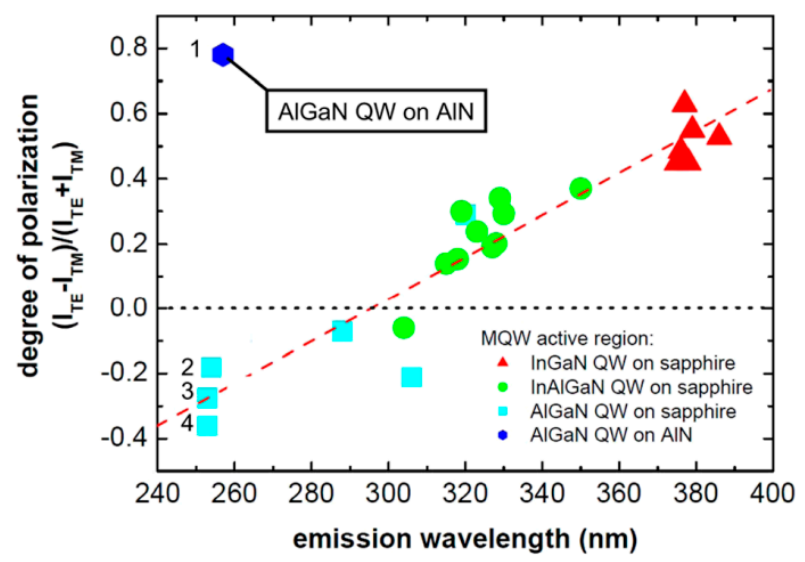

Figure 8. Degree of polarization of emission from LEDs fabricated on sapphire or AlN substrates. For the devices grown on sapphire, TE polarization is obtained at wavelengths greater than $\sim 310 \mathrm{~nm}$ and TM polarization is obtained for wavelengths less than $\sim 310 \mathrm{~nm}$. Device 1, in the upper left hand corner represents a different approach in that its active region consisting of short period AlGaN/AlGaN quantum wells was pseudomorphically grown on AlN. As depicted, it emits highly TE polarized light at $253 \mathrm{~nm}$. The quantum wells in Devices 2-4 (cyan colored squares) are identical in design to Device 1 but are grown on sapphire. The long dashed line is intended to illustrate the trend for LEDs grown on sapphire while the horizontal dotted line depicts the case of equally split polarization. Reprinted from [92], with the permission of AIP publishing.

\section{AlN/AlGaN Superlattice Buffer}

One important approach used to improve the material quality of AlGaN-based heterosturctures is via $\mathrm{AlN} / \mathrm{AlGaN}$ (or AlGaN/AlGaN) superlattice buffer. The utility of AlN/AlGaN superlattice in relieving strain for DUV LEDs was proposed as far back as in 2002. Zhang et al. [95] demonstrated the utility of ten period $\mathrm{AlN} / \mathrm{Al}_{0.2} \mathrm{Ga}_{0.8} \mathrm{~N}$ superlattices, inserted between HT-AlN/LT-AlN/sapphire composite and the n-type AlGaN layer, in significantly reducing the biaxial tensile strain in the $\mathrm{n}$-AlGaN layer, allowing $3 \mu \mathrm{m}$ thick crack-free $\mathrm{Al}_{0.2} \mathrm{Ga}_{0.8} \mathrm{~N}$ films. Later Wang et al. [96] reported that AlN/AlGaN superlattice buffer also acts as a dislocation filter for TDD reduction in AlGaN layers on sapphire substrate. This buffer was found to greatly enlarge the coherence lengths of mosaic blocks and reduce the TDD by two orders of magnitude in $\mathrm{Al}_{0.2} \mathrm{Ga}_{0.8} \mathrm{~N}$ layers. $\mathrm{Xi}$ et al. [97] conducted a comparative study of n-type AlGaN grown on sapphire by using a superlattice buffer and a LT-AlN interlayer. Improved electrical properties with higher electron concentration and mobility and surface morphologies, lacking hexagonal hillocks on the $\mathrm{Al}_{0.3} \mathrm{Ga}_{0.7} \mathrm{~N}$ surface, was achieved in samples with AlN/AlGaN or AlGaN/AlGaN superlattice buffer, compared with samples with only a LT-AlN interlayer buffer [97].

Chitnis et al. [98] also demonstrated improved performance in DUV LEDs with AlN/AlGaN superlattice buffer layer. By using the pulsed atomic layer epitaxy (PALE) approach discussed in Section 6, and an $\mathrm{AlN} / \mathrm{Al}_{0.85} \mathrm{Ga}_{0.15} \mathrm{~N}$ superlattice strain-relief buffer, output power levels of $10.2 \mathrm{~mW}$ at $1 \mathrm{~A}$ pulsed current and $1 \mathrm{~mW}$ at $100 \mathrm{~mA} \mathrm{CW}$ current were achieved in LEDs emitting at $325 \mathrm{~nm}$ and grown on sapphire substrates. In recently developed high-power DUV LEDs, the AlN/AlGaN superlattice buffer approach was employed by several groups $[4,16]$. For example, the LEDs emitting at $278 \mathrm{~nm}$ with an EQE of $10.4 \%$ and an output power of $9.3 \mathrm{~mW}$ at $20 \mathrm{~mA} \mathrm{CW}$ current utilized strain-relief AlN/AlGaN superlattices on $10 \mu \mathrm{m}$ thick AlN layers by migration-enhanced metalorganic chemical vapor deposition (MEMOCVD) [4]. In 255, 280, and $310 \mathrm{~nm}$ DUV LEDs with output powers 
of $45.2,93.3$, and $65.8 \mathrm{~mW}$ and EQEs of $1.3 \%, 3.0 \%$, and $2.4 \%$, respectively, at $350 \mathrm{~mA}$ pulsed current, $\mathrm{AlN} / \mathrm{AlGaN}$ superlattices were also implemented as a basic design strategy for strain-relief [16].

\section{Doping Considerations in High Al-Molar Fraction AlGaN}

As is well known, the remarkable progress in group III-nitride LEDs hinged on the achievement of p-type doping in GaN. However, non-transparency of p-GaN for emission wavelengths below $365 \mathrm{~nm}$ leads to significant self-absorption and a very low LEE of DUV LEDs. In addition, the large barrier between p-type $\mathrm{GaN}$ and high Al-molar fraction AlGaN electron blocking layer (EBL) hinders the injection efficiency of holes. To overcome these obstacles, researchers have focused on developing transparent $\mathrm{p}-\mathrm{AlGaN}$ with improved hole conductivity to replace the $\mathrm{p}-\mathrm{GaN}$ layer [8], as schematically shown in Figure 9. The factors limiting the conductivity of p-AlGaN include severe self-compensation by donor-like defects that are produced simultaneously, limited dopant solubility, and increasingly high acceptor activation energy of $\mathrm{Mg}$ dopant with increasing $\mathrm{Al}$ molar fraction-the activation energy reaches $\sim 400 \mathrm{meV}$ for an $\mathrm{Al}$ fraction of 70\% [99], and is as high as $510 \sim 630 \mathrm{meV}$ for AlN [100,101]. Therefore, numerous efforts have been undertaken to mitigate compensation by decreasing donor defects and increasing solubility of the dopants, increasing the hole mobility by reducing the scattering rate, and increasing the acceptor activation rate by reducing the activation energy through polarization field. The approaches include co-doping of Mg with Si or oxygen [102,103], Mg delta-doping [104,105], and $\mathrm{Mg}$-doped $\mathrm{Al}_{x} \mathrm{Ga}_{1-\mathrm{x}} \mathrm{N} / \mathrm{AlN}$ superlattice or $\mathrm{Al}_{x} \mathrm{Ga}_{1-\mathrm{x}} \mathrm{N} / \mathrm{Al}_{\mathrm{y}} \mathrm{Ga}_{1-\mathrm{y}} \mathrm{N}$ superlattice $[106,107]$. Some of the reports on the achievement of low p-type resistivities in high Al-molar fraction AlGaN are overviewed below.

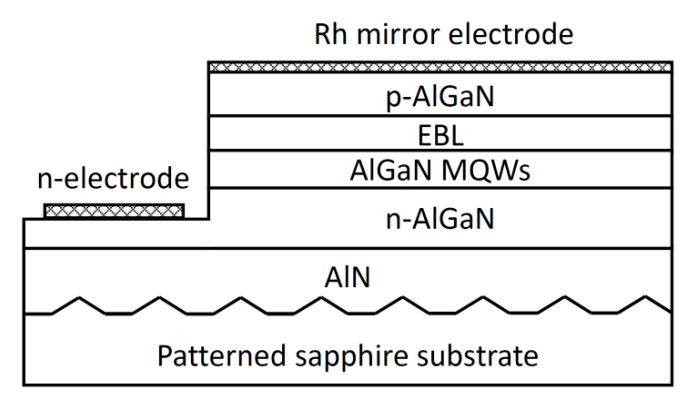

Figure 9. Schematic of UV LED structures with a transparent p-type AlGaN: Mg contact layer and a Rh mirror electrode. After Reference [8].

Kakanakova-Georgieva et al. estimated a hole concentration of $\sim 10^{14} \mathrm{~cm}^{-3}$ for Mg-doped $\mathrm{Al}_{0.85} \mathrm{Ga}_{0.15} \mathrm{~N}$ layers, from the a room temperature resistivity of $7 \mathrm{k} \Omega \mathrm{cm}$ by assuming a hole mobility of $2 \mathrm{~cm}^{2} \mathrm{~V}^{-1} \mathrm{~s}^{-1}$, when grown using a hot wall MOCVD system which purportedly leads to growth conditions for reduced compensation by native defects [108]. The same authors also reported a resistivity of $2 \mathrm{k} \Omega \mathrm{cm}$ and $60 \Omega \mathrm{cm}$ for $\mathrm{Al}_{0.70} \mathrm{Ga}_{0.30} \mathrm{~N}$ and $\mathrm{Al}_{0.60} \mathrm{Ga}_{0.40} \mathrm{~N}$, respectively, by using the hot wall MOCVD reactor with optimized V/III ratio [109]. If the same hole mobility of $2 \mathrm{~cm}^{2} \mathrm{~V}^{-1} \mathrm{~s}^{-1}$ is assumed, the hole concentrations in the $\mathrm{Al}_{0.70} \mathrm{Ga}_{0.30} \mathrm{~N}$ and $\mathrm{Al}_{0.60} \mathrm{Ga}_{0.40} \mathrm{~N}$ layers are deduced to be $\sim 3.5 \times 10^{14} \mathrm{~cm}^{-3}$ and $\sim 1 \times 10^{16} \mathrm{~cm}^{-3}$, respectively. Through the optimization of growth conditions, highly conductive p-type $\mathrm{Mg}$-doped $\mathrm{Al}_{0.70} \mathrm{Ga}_{0.30} \mathrm{~N}$ thin films were realized by employing a high $\mathrm{V} / \mathrm{III}$ ratio and moderate $\mathrm{Mg}$ concentration by Kinoshita et al. [110] Such conditions were found to effectively suppress self-compensation by the formation of nitrogen vacancy complexes, which are considered to be the compensating donors. An electrical resistivity as low as $47 \Omega \mathrm{cm}$ and a hole concentration of $1.3 \times 10^{17} \mathrm{~cm}^{-3}$ was achieved with an $\mathrm{Mg}$ concentration of $3.9 \times 10^{19} \mathrm{~cm}^{-3}$ at room temperature.

Mg-doped $\mathrm{Al}_{\mathrm{x}} \mathrm{Ga}_{1-\mathrm{x}} \mathrm{N} / \mathrm{AlN}$ superlattice or $\mathrm{Al}_{\mathrm{x}} \mathrm{Ga}_{1-\mathrm{x}} \mathrm{N} / \mathrm{Al}_{\mathrm{y}} \mathrm{Ga}_{1-\mathrm{y}} \mathrm{N}$ superlattice with alternating low and high $\mathrm{Al}$ composition has been employed to obtain relatively high p-type conductivity $[106,107]$. The mechanism for hole enhancement is the periodic modulation of the valence-band edge. Acceptors are ionized where the band edge is far below the Fermi energy set by the lower Al-molar fraction 
regions, and the resulting holes accumulate where the band edge is close to the Fermi level, forming a confined sheet of carriers, as schematically illustrated in Figure 10. Although the free carriers are separated into parallel sheets, their spatially averaged density will be much higher than in a standard bulk film. The effective activation energy was determined to be $29 \mathrm{meV}$ in $\mathrm{Mg}$-doped $\mathrm{Al}_{\mathrm{x}} \mathrm{Ga}_{1-\mathrm{x}} \mathrm{N} / \mathrm{AlN}$ superlattices with an average $\mathrm{Al}$ composition of 0.62 , and $18 \mathrm{meV}$ with an average $\mathrm{Al}$ composition of 0.49 [106]. P-type resistivities below $10 \Omega \mathrm{cm}$ were measured in superlattice structures with an average $\mathrm{Al}$ composition from 0.49 to 0.74 . As an additional benefit, $\mathrm{Al}_{x} \mathrm{Ga}_{1-\mathrm{x}} \mathrm{N} / \mathrm{AlN}$ superlattices with periods of $20 \AA$ or less have shown optical transparency similar to random alloy $\mathrm{Al}_{\mathrm{x}} \mathrm{Ga}_{1-\mathrm{x}} \mathrm{N}$ epilayers of the same average composition, indicating the potential of this approach for DUV LEDs [106].

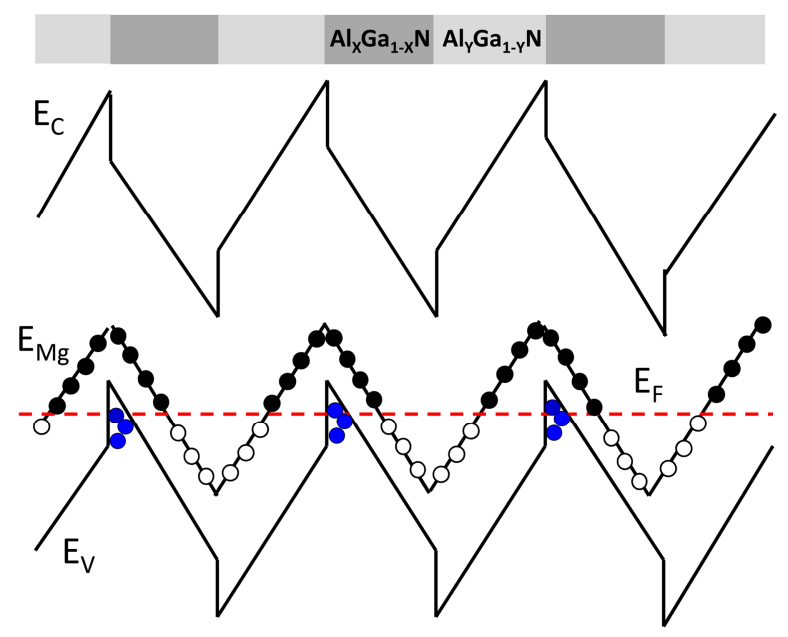

Figure 10. Schematic of the band structure of an $\mathrm{Mg}$-doped $\mathrm{Al}_{\mathrm{x}} \mathrm{Ga}_{1-\mathrm{x}} \mathrm{N} / \mathrm{Al}_{\mathrm{y}} \mathrm{Ga}_{1-\mathrm{y}} \mathrm{N}(\mathrm{x}<\mathrm{y})$ superlattice. The dashed red line represents the Fermi energy; the empty circles represent the energy of the $\mathrm{Mg}$ acceptor when ionized, and the blue solid circles represent the accumulation of holes at the heterointerfaces.

Compared with p-type doping, n-type doping of high Al-molar fraction AlGaN is relatively straightforward. For AlGaN with Al-molar fraction below 50\%, the activation energy of Si remains at very low values similar to that in $\mathrm{GaN}(15-25 \mathrm{meV})$ [44]. Therefore the Si dopants can still be almost completely activated, and electron concentrations above $10^{18} \mathrm{~cm}^{-3}$ are typically obtained. For AlGaN with Al-molar fraction above $80 \%$, both the activation energy of Si dopants and the self-compensation effect increase sharply with increasing Al-molar fraction [100,111]. These result in a rapid drop in the achievable electron concentrations with increasing Al-molar fraction. Taking advantage of the pseudomorphic growth, electrical resistivities below $0.1 \Omega \mathrm{cm}$ were reported by Collazo et al. [44] for n-type AlGaN films with Al-molar fraction below $85 \%$ grown pseudomorphically on bulk AlN. An electron concentration of $\sim 1 \times 10^{18} \mathrm{~cm}^{-3}$ and an electron mobility above $40 \mathrm{~cm}^{2} /$ Vs were obtained for a film with Al-molar fraction of $80 \%$ and a Si doping concentration of $6 \times 10^{18} \mathrm{~cm}^{-3}$ [44]. By optimizing $\mathrm{SiH}_{4} /$ group-III ratio, Mehnke et al. [112] achieved a resistivity of $0.026 \Omega \mathrm{cm}$ for $\mathrm{Al}_{0.81} \mathrm{Ga}_{0.19} \mathrm{~N}$ epilayers pseudomorphically grown on low defect density ELO AlN/sapphire templates, with an electron concentration of $1.5 \times 10^{19} \mathrm{~cm}^{-3}$ and a mobility of $16.5 \mathrm{~cm}^{2} / \mathrm{Vs}$. These values are thought to be sufficient for efficient operation of DUV LEDs with an emission wavelength of $250-260 \mathrm{~nm}$.

\section{Conclusions}

We have provided a succinct overview of the recent progress in growth of III-nitride heterostructures for DUV LEDs, with particular emphasis on growth of AIN and growth and doping of high Al-molar fraction AlGaN. Although at this stage, the efficiency of DUV LEDs is behind 
those operating in the near UV and the visible spectra ranges, one can be optimistic in that the efficiencies and output powers of DUV LEDs will continue to increase in the near future and EQEs of tens of percent are achievable. Homoepitaxial growth on bulk AlN crystals looks attractive barring cost concerns. The developments in bulk AlN single crystals have already led to superior device performance as compared to those on foreign substrates owing to reduced defect density in the films. Wider applications on AlN bulk crystal substrates are expected with further improvements in the bulk crystal growth technologies together with needed reduction in cost. Pseudomorphic growth of strained AlGaN has shown the capability of growing high-quality epilayers with TDDs comparable to the starting substrate and driving the critical Al-molar fraction up to $80 \%$, at which polarization of emitted light switches from TE to TM mode, thus improving both IQE and light extraction efficiency. Optimized heterostructure design, which includes AlGaN multi-quantum barrier as electron blocking layer, has enabled a marked increase in electron injection efficiency. New strategies such as AlN pillar arrays, sidewall emission-enhanced chip geometry, and durable encapsulation have also shown their potential in light extraction enhancement. The combination of advanced material growth approaches, device design, and light extraction strategies stand to make DUV LEDs more efficient in the future.

Acknowledgments: The authors would like to thank M. Kneissl of Technische Universität Berlin for providing the original version of Figure 1.

Author Contributions: All the authors have participated in the literature review and in the correction and revision of the manuscript.

Conflicts of Interest: The authors declare no conflict of interest.

\section{References}

1. Pernot, C.; Kim, M.; Fukahori, S.; Inazu, T.; Fujita, T.; Nagasawa, Y.; Hirano, A.; Ippommatsu, M.; Iwaya, M.; Kamiyama, S.; et al. Improved efficiency of 255-280 nm AlGaN-based light-emitting diodes. Appl. Phys. Express 2010, 3, 061004. [CrossRef]

2. Grandusky, J.R.; Gibb, S.R.; Mendrick, M.C.; Moe, C.; Wraback, M.; Schowalter, L.J. High output power from $260 \mathrm{~nm}$ pseudomorphic ultraviolet light-emitting diodes with improved thermal performance. Appl. Phys. Express 2011, 4, 082101. [CrossRef]

3. Grandusky, J.R.; Chen, J.; Gibb, S.R.; Mendrick, M.C.; Moe, C.G.; Rodak, L.; Garrett, G.A.; Wraback, M.; Schowalter, L.J. $270 \mathrm{~nm}$ pseudomorphic ultraviolet light-emitting diodes with over $60 \mathrm{mw}$ continuous wave output power. Appl. Phys. Express 2013, 6, 032101. [CrossRef]

4. Shatalov, M.; Sun, W.; Lunev, A.; Hu, X.; Dobrinsky, A.; Bilenko, Y.; Yang, J.; Shur, M.; Gaska, R.; Moe, C.; et al. AlGaN deep-ultraviolet light-emitting diodes with external quantum efficiency above 10\%. Appl. Phys. Express 2012, 5, 082101. [CrossRef]

5. Inoue, S.-I.; Naoki, T.; Kinoshita, T.; Obata, T.; Yanagi, H. Light extraction enhancement of $265 \mathrm{~nm}$ deep-ultraviolet light-emitting diodes with over $90 \mathrm{mw}$ output power via an AlN hybrid nanostructure. Appl. Phys. Lett. 2015, 106, 131104. [CrossRef]

6. Maeda, N.; Hirayama, H. Realization of high-efficiency deep-UV LEDs using transparent p-AlGaN contact layer. Phys. Stat. Sol. C 2013, 10, 1521-1524. [CrossRef]

7. Hirayama, H.; Takano, T.; Sakai, J.; Mino, T.; Tsubaki, K.; Maeda, N.; Jo, M.; Kanazawa, Y.; Ohshima, I.; Matsumoto, T. Realization of Over 10\% EQE AlGaN Deep-UV LED by Using Transparent p-AlGaN Contact Layer. In Proceedings of the 2016 International Semiconductor Laser Conference (ISLC), 12-15 September 2016; pp. 1-2.

8. Takano, T.; Mino, T.; Sakai, J.; Noguchi, N.; Tsubaki, K.; Hirayama, H. Deep-ultraviolet light-emitting diodes with external quantum efficiency higher than $20 \%$ at $275 \mathrm{~nm}$ achieved by improving light-extraction efficiency. Appl. Phys. Express 2017, 10, 031002. [CrossRef]

9. Kinoshita, T.; Obata, T.; Nagashima, T.; Yanagi, H.; Moody, B.; Mita, S.; Inoue, S.-I.; Kumagai, Y.; Koukitu, A.; Sitar, Z. Performance and reliability of deep-ultraviolet light-emitting diodes fabricated on AlN substrates prepared by hydride vapor phase epitaxy. Appl. Phys. Express 2013, 6, 092103. [CrossRef] 
10. Moe, C.G.; Grandusky, J.R.; Chen, J.; Kitamura, K.; Mendrick, M.C.; Jamil, M.; Toita, M.; Gibb, S.R.; Schowalter, L.J. High-power pseudomorphic mid-ultraviolet light-emitting diodes with improved efficiency and lifetime. Proc. SPIE 2014, 8986, 89861V.

11. Hwang, S.; Morgan, D.; Kesler, A.; Lachab, M.; Zhang, B.; Heidari, A.; Nazir, H.; Ahmad, I.; Dion, J.; Fareed, Q.; et al. $276 \mathrm{~nm}$ substrate-free flip-chip AlGaN light-emitting diodes. Appl. Phys. Express 2011, 4, 032102. [CrossRef]

12. Fujioka, A.; Misaki, T.; Murayama, T.; Narukawa, Y.; Mukai, T. Improvement in output power of 280-nm deep ultraviolet light-emitting diode by using AlGaN multi quantum wells. Appl. Phys. Express 2010, 3, 041001. [CrossRef]

13. Kneissl, M.; Kolbe, T.; Chua, C.; Kueller, V.; Lobo, N.; Stellmach, J.; Knauer, A.; Rodriguez, H.; Einfeldt, S.; Yang, Z.; et al. Advances in group III-nitride-based deep UV light-emitting diode technology. Semicon. Sci. Tech. 2011, 26, 014036. [CrossRef]

14. Kolbe, T.; Mehnke, F.; Guttmann, M.; Kuhn, C.; Rass, J.; Wernicke, T.; Kneissl, M. Improved injection efficiency in $290 \mathrm{~nm}$ light emitting diodes with $\mathrm{Al}(\mathrm{Ga}) \mathrm{N}$ electron blocking heterostructure. Appl. Phys. Lett. 2013, 103, 031109. [CrossRef]

15. Dong, P.; Yan, J.; Wang, J.; Zhang, Y.; Geng, C.; Wei, T.; Cong, P.; Zhang, Y.; Zeng, J.; Tian, Y.; et al. 282-nm AlGaN-based deep ultraviolet light-emitting diodes with improved performance on nano-patterned sapphire substrates. Appl. Phys. Lett. 2013, 102, 241113. [CrossRef]

16. Fujioka, A.; Asada, K.; Yamada, H.; Ohtsuka, T.; Ogawa, T.; Kosugi, T.; Kishikawa, D.; Mukai, T. High-output-power 255/280/310 nm deep ultraviolet light-emitting diodes and their lifetime characteristics. Semicon. Sci. Tech. 2014, 29, 084005. [CrossRef]

17. Hirayama, H.; Maeda, N.; Fujikawa, S.; Toyoda, S.; Kamata, N. Recent progress and future prospects of AlGaN-based high-efficiency deep-ultraviolet light-emitting diodes. Jpn. J. Appl. Phys. 2014, 53, 100209. [CrossRef]

18. Kneissl, M.; Rass, J. III-Nitride Ultraviolet Emitters. In Springer Series in Materials Science; Springer International Publishing: Cham, Switzerland, 2016; Volume 277.

19. Hirayama, H. Growth techniques of AlN/AlGaN and development of high-efficiency deep-ultraviolet light-emitting diodes. In III-Nitride Ultraviolet Emitters; Springer: Berlin, Germany, 2016; pp. 75-113.

20. Hirayama, H.; Fujikawa, S.; Kamata, N. Recent progress in ALGaN-based deep-UV LEDs. Electron. Commun. Jpn. 2015, 98, 1-8. [CrossRef]

21. Yasan, A.; McClintock, R.; Mayes, K.; Shiell, D.; Gautero, L.; Darvish, S.R.; Kung, P.; Razeghi, M. 4.5 mw operation of AlGaN-based $267 \mathrm{~nm}$ deep-ultraviolet light-emitting diodes. Appl. Phys. Lett. 2003, 83, 4701-4703. [CrossRef]

22. Shatalov, M.; Chitnis, A.; Yadav, P.; Hasan, M.F.; Khan, J.; Adivarahan, V.; Maruska, H.P.; Sun, W.H.; Khan, M.A. Thermal analysis of flip-chip packaged $280 \mathrm{~nm}$ nitride-based deep ultraviolet light-emitting diodes. Appl. Phys. Lett. 2005, 86, 201109. [CrossRef]

23. Ryu, H.-Y.; Choi, I.-G.; Choi, H.-S.; Shim, J.-I. Investigation of light extraction efficiency in AlGaN deep-ultraviolet light-emitting diodes. Appl. Phys. Express 2013, 6, 062101. [CrossRef]

24. Inoue, S.-I.; Tamari, N.; Taniguchi, M. $150 \mathrm{mw}$ deep-ultraviolet light-emitting diodes with large-area AlN nanophotonic light-extraction structure emitting at $265 \mathrm{~nm}$. Appl. Phys. Lett. 2017, 110, 141106. [CrossRef]

25. Kim, D.Y.; Park, J.H.; Lee, J.W.; Hwang, S.; Oh, S.J.; Kim, J.; Sone, C.; Schubert, E.F.; Kim, J.K. Overcoming the fundamental light-extraction efficiency limitations of deep ultraviolet light-emitting diodes by utilizing transverse-magnetic-dominant emission. Light Sci. Appl. 2015, 4, e263. [CrossRef]

26. Lee, J.W.; Kim, D.Y.; Park, J.H.; Schubert, E.F.; Kim, J.; Lee, J.; Kim, Y.I.; Park, Y.; Kim, J.K. An elegant route to overcome fundamentally-limited light extraction in AlGaN deep-ultraviolet light-emitting diodes: Preferential outcoupling of strong in-plane emission. Sci. Rep. 2016, 6, 22537. [CrossRef] [PubMed]

27. Ichikawa, M.E.S.; Sagawa, H.; Fujioka, A.; Kosugi, T.; Mukai, T.; Uomoto, M.; Shimatsu, T. High output power deep ultraviolet light-emitting diodes with hemispherical lenses fabricated using room temperature bonding. ECS Trans. 2016, 75, 53-65. [CrossRef]

28. Nagai, S.; Yamada, K.; Hirano, A.; Ippommatsu, M.; Ito, M.; Morishima, N.; Aosaki, K.; Honda, Y.; Amano, H.; Akasaki, I. Development of highly durable deep-ultraviolet AlGaN-based led multichip array with hemispherical encapsulated structures using a selected resin through a detailed feasibility study. Jpn. J. Appl. Phys. 2016, 55, 082101. [CrossRef] 
29. Yamada, K.; Furusawa, Y.; Nagai, S.; Hirano, A.; Ippommatsu, M.; Aosaki, K.; Morishima, N.; Amano, H.; Akasaki, I. Development of underfilling and encapsulation for deep-ultraviolet LEDs. Appl. Phys. Express 2015, 8, 012101. [CrossRef]

30. Hirano, A.; Nagasawa, Y.; Ippommatsu, M.; Aosaki, K.; Honda, Y.; Amano, H.; Akasaki, I. Development of AlGaN-based deep-ultraviolet (DUV) LEDs focusing on the fluorine resin encapsulation and the prospect of the practical applications. Proc. SPIE 2016, 9926, 99260C.

31. Fujito, K.; Kubo, S.; Nagaoka, H.; Mochizuki, T.; Namita, H.; Nagao, S. Bulk GaN crystals grown by HVPE. J. Cryst. Growth 2009, 311, 3011-3014. [CrossRef]

32. Dwiliński, R.; Doradziński, R.; Garczyński, J.; Sierzputowski, L.; Kucharski, R.; Zając, M.; Rudziński, M.; Kudrawiec, R.; Strupiński, W.; Misiewicz, J. Ammonothermal GaN substrates: Growth accomplishments and applications. Phys. Stat. Sol. A 2011, 208, 1489-1493. [CrossRef]

33. Levinshtein, M.E.; Rumyantsev, S.L.; Shur, M.S. Properties of Advanced Semiconductor Materials: GaN, AlN, InN, BN, SiC, SiGe; John Wiley \& Sons: Hoboken, NJ, USA, 2001.

34. Morkoç, H. Handbook of Nitride Semiconductors and Devices, Materials Properties, Physics and Growth; John Wiley \& Sons: Hoboken, NJ, USA, 2009; Volume 1.

35. Mueller, S.G.; Bondokov, R.T.; Morgan, K.E.; Slack, G.A.; Schujman, S.B.; Grandusky, J.; Smart, J.A.; Schowalter, L.J. The progress of AlN bulk growth and epitaxy for electronic applications. Phys. Stat. Sol. A 2009, 206, 1153-1159. [CrossRef]

36. Ehrentraut, D.; Sitar, Z. Advances in bulk crystal growth of AlN and GaN. MRS Bull. 2009, 34, $259-265$. [CrossRef]

37. Herro, Z.G.; Zhuang, D.; Schlesser, R.; Collazo, R.; Sitar, Z. Seeded growth of AlN on N- and Al-polar AlN seeds by physical vapor transport. J. Cryst. Growth 2006, 286, 205-208. [CrossRef]

38. Helava, H.; Chemekova, T.J.; Avdeev, O.; Mokhov, E.; Nagalyuk, S.; Makarov, Y.; Ramm, M. AlN substrates and epitaxy results. Phys. Stat. Sol. C 2010, 7, 2115-2117. [CrossRef]

39. Herro, Z.G.; Zhuang, D.; Schlesser, R.; Sitar, Z. Growth of AlN single crystalline boules. J. Cryst. Growth 2010, 312, 2519-2521. [CrossRef]

40. Nagai, I.; Kato, T.; Miura, T.; Kamata, H.; Naoe, K.; Sanada, K.; Okumura, H. AlN bulk single crystal growth on 6H-SiC substrates by sublimation method. J. Cryst. Growth 2010, 312, 2699-2704. [CrossRef]

41. Makarov, Y.N.; Avdeev, O.V.; Barash, I.S.; Bazarevskiy, D.S.; Chemekova, T.Y.; Mokhov, E.N.; Nagalyuk, S.S.; Roenkov, A.D.; Segal, A.S.; Vodakov, Y.A.; et al. Experimental and theoretical analysis of sublimation growth of AlN bulk crystals. J. Cryst. Growth 2008, 310, 881-886. [CrossRef]

42. Hartmann, C.; Dittmar, A.; Wollweber, J.; Bickermann, M. Bulk AlN growth by physical vapour transport. Semicon. Sci. Tech. 2014, 29, 084002. [CrossRef]

43. Ren, Z.; Sun, Q.; Kwon, S.Y.; Han, J.; Davitt, K.; Song, Y.K.; Nurmikko, A.V.; Liu, W.; Smart, J.; Schowalter, L. AlGaN deep ultraviolet LEDs on bulk AlN substrates. Phys. Stat. Sol. C 2007, 4, 2482-2485. [CrossRef]

44. Collazo, R.; Mita, S.; Xie, J.; Rice, A.; Tweedie, J.; Dalmau, R.; Sitar, Z. Progress on n-type doping of AlGaN alloys on AlN single crystal substrates for UV optoelectronic applications. Phys. Stat. Sol. C 2011, 8, 2031-2033. [CrossRef]

45. Grandusky, J.R.; Gibb, S.R.; Mendrick, M.C.; Schowalter, L.J. Properties of mid-ultraviolet light emitting diodes fabricated from pseudomorphic layers on bulk aluminum nitride substrates. Appl. Phys. Express 2010, 3, 072103. [CrossRef]

46. Bryan, Z.; Bryan, I.; Xie, J.; Mita, S.; Sitar, Z.; Collazo, R. High internal quantum efficiency in AlGaN multiple quantum wells grown on bulk AlN substrates. Appl. Phys. Lett. 2015, 106, 142107. [CrossRef]

47. Bickermann, M.; Epelbaum, B.M.; Filip, O.; Heimann, P.; Nagata, S.; Winnacker, A. UV transparent single-crystalline bulk AlN substrates. Phys. Stat. Sol. C 2010, 7, 21-24. [CrossRef]

48. Bickermann, M.; Epelbaum, B.M.; Filip, O.; Tautz, B.; Heimann, P.; Winnacker, A. Faceting in AlN bulk crystal growth and its impact on optical properties of the crystals. Phys. Stat. Sol. C 2012, 9, 449-452. [CrossRef]

49. Tuomisto, F.; Mäki, J.M.; Chemekova, T.Y.; Makarov, Y.N.; Avdeev, O.V.; Mokhov, E.N.; Segal, A.S.; Ramm, M.G.; Davis, S.; Huminic, G.; et al. Characterization of bulk AlN crystals with positron annihilation spectroscopy. J. Cryst. Growth 2008, 310, 3998-4001. [CrossRef]

50. Sumathi, R.R.; Gille, P. Development and progress in bulk c-plane AlN single-crystalline template growth for large-area native seeds. Jpn. J. Appl. Phys. 2013, 52, 08JA02. [CrossRef] 
51. Collazo, R.; Xie, J.; Gaddy, B.E.; Bryan, Z.; Kirste, R.; Hoffmann, M.; Dalmau, R.; Moody, B.; Kumagai, Y.; Nagashima, T.; et al. On the origin of the $265 \mathrm{~nm}$ absorption band in AlN bulk crystals. Appl. Phys. Lett. 2012, 100, 191914. [CrossRef]

52. Hartmann, C.; Wollweber, J.; Dittmar, A.; Irmscher, K.; Kwasniewski, A.; Langhans, F.; Neugut, T.; Bickermann, M. Preparation of bulk AlN seeds by spontaneous nucleation of freestanding crystals. Jpn. J. Appl. Phys. 2013, 52, 08JA06. [CrossRef]

53. Sedhain, A.; Du, L.; Edgar, J.H.; Lin, J.Y.; Jiang, H.X. The origin of 2.78 ev emission and yellow coloration in bulk AlN substrates. Appl. Phys. Lett. 2009, 95, 262104. [CrossRef]

54. Kumagai, Y.; Enatsu, Y.; Ishizuki, M.; Kubota, Y.; Tajima, J.; Nagashima, T.; Murakami, H.; Takada, K.; Koukitu, A. Investigation of void formation beneath thin AlN layers by decomposition of sapphire substrates for self-separation of thick AlN layers grown by HVPE. J. Cryst. Growth 2010, 312, 2530-2536. [CrossRef]

55. Kumagai, Y.; Nagashima, T.; Koukitu, A. Preparation of a freestanding AlN substrate by hydride vapor phase epitaxy at $1230 \mathrm{c}$ using (111) Si as a starting substrate. Jpn. J. Appl. Phys. 2007, 46, L389. [CrossRef]

56. Nomura, T.; Okumura, K.; Miyake, H.; Hiramatsu, K.; Eryu, O.; Yamada, Y. AlN homoepitaxial growth on sublimation-AlN substrate by low-pressure HVPE. J. Cryst. Growth 2012, 350, 69-71. [CrossRef]

57. Kumagai, Y.; Kubota, Y.; Nagashima, T.; Kinoshita, T.; Dalmau, R.; Schlesser, R.; Moody, B.; Xie, J.; Murakami, H.; Koukitu, A.; et al. Preparation of a freestanding AlN substrate from a thick AlN layer grown by hydride vapor phase epitaxy on a bulk AlN substrate prepared by physical vapor transport. Appl. Phys. Express 2012, 5, 055504. [CrossRef]

58. Kinoshita, T.; Hironaka, K.; Obata, T.; Nagashima, T.; Dalmau, R.; Schlesser, R.; Moody, B.; Xie, J.; Inoue, S.-i.; Kumagai, Y.; et al. Deep-ultraviolet light-emitting diodes fabricated on AlN substrates prepared by hydride vapor phase epitaxy. Appl. Phys. Express 2012, 5, 122101. [CrossRef]

59. Brunner, F.; Protzmann, H.; Heuken, M.; Knauer, A.; Weyers, M.; Kneissl, M. High-temperature growth of AlN in a production scale $11 \times 2$ ' movpe reactor. Phys. Stat. Sol. C 2008, 5, 1799-1801. [CrossRef]

60. Chichibu, S.F.; Onuma, T.; Hazu, K.; Uedono, A. Major impacts of point defects and impurities on the carrier recombination dynamics in AlN. Appl. Phys. Lett. 2010, 97, 201904. [CrossRef]

61. Chichibu, S.F.; Onuma, T.; Hazu, K.; Uedono, A. Time-resolved luminescence studies on AlN and high AlN mole fraction AlGaN alloys. Phys. Stat. Sol. C 2013, 10, 501-506. [CrossRef]

62. Onuma, T.; Hazu, K.; Uedono, A.; Sota, T.; Chichibu, S.F. Identification of extremely radiative nature of AlN by time-resolved photoluminescence. Appl. Phys. Lett. 2010, 96, 061906. [CrossRef]

63. Hirayama, H.; Fujikawa, S.; Noguchi, N.; Norimatsu, J.; Takano, T.; Tsubaki, K.; Kamata, N. $222-282$ nm AlGaN and in AlGaN-based deep-UV LEDs fabricated on high-quality AlN on sapphire. Phys. Stat. Sol. A 2009, 206, 1176-1182. [CrossRef]

64. Hirayama, H.; Yatabe, T.; Noguchi, N.; Ohashi, T.; Kamata, N. 231-261nm AlGaN deep-ultraviolet light-emitting diodes fabricated on AlN multilayer buffers grown by ammonia pulse-flow method on sapphire. Appl. Phys. Lett. 2007, 91, 071901. [CrossRef]

65. Zhang, J.; Kuokstis, E.; Fareed, Q.; Wang, H.; Yang, J.; Simin, G.; Khan, M.A.; Gaska, R.; Shur, M. Pulsed atomic layer epitaxy of quaternary AlInGaN layers. Appl. Phys. Lett. 2001, 79, 925-927. [CrossRef]

66. Zhang, J.P.; Khan, M.A.; Sun, W.H.; Wang, H.M.; Chen, C.Q.; Fareed, Q.; Kuokstis, E.; Yang, J.W. Pulsed atomic-layer epitaxy of ultrahigh-quality $\mathrm{AlxGa}_{1-\mathrm{x}} \mathrm{N}$ structures for deep ultraviolet emissions below 230 nm. Appl. Phys. Lett. 2002, 81, 4392-4394. [CrossRef]

67. Bilenko, Y.; Lunev, A.; Hu, X.; Deng, J.; Katona, T.M.; Zhang, J.; Gaska, R.; Shur, M.S.; Sun, W.; Adivarahan, V. 10 milliwatt pulse operation of $265 \mathrm{~nm}$ AlGaN light emitting diodes. Jpn. J. Appl. Phys. 2004, 44, L98. [CrossRef]

68. Sun, W.H.; Yang, J.W.; Zhang, J.P.; Gaevski, M.E.; Chen, C.Q.; Li, J.W.; Gong, Z.; Su, M.; Asif Khan, M. $\mathrm{n}-\mathrm{Al}_{0.75} \mathrm{Ga}_{0.25} \mathrm{~N}$ epilayers for $250 \mathrm{~nm}$ emission ultraviolet light emitting diodes. Phys. Stat. Sol. C 2005, 2, 2083-2086. [CrossRef]

69. Shatalov, M.; Jain, R.; Saxena, T.; Dobrinsky, A.; Shur, M. Chapter two-development of deep UV LEDs and current problems in material and device technology. Semicond. Semimet. 2017, 96, 45-83.

70. Hirayama, H.; Yatabe, T.; Noguchi, N.; Ohashi, T.; Kamata, N. 226-273 nm AlGaN deep-ultraviolet light-emitting diodes fabricated on multilayer AlN buffers on sapphire. Phys. Stat. Sol. C 2008, 5, 2969-2971. [CrossRef] 
71. Zhang, J.; Wang, H.; Sun, W.; Adivarahan, V.; Wu, S.; Chitnis, A.; Chen, C.; Shatalov, M.; Kuokstis, E.; Yang, J. High-quality AlGaN layers over pulsed atomic-layer epitaxially grown AlN templates for deep ultraviolet light-emitting diodes. J. Electr. Mater. 2003, 32, 364-370. [CrossRef]

72. Shur, M.S.; Gaska, R. Deep-ultraviolet light-emitting diodes. IEEE Trans. Electr. Devices 2010, 57, 12-25. [CrossRef]

73. Kueller, V.; Knauer, A.; Reich, C.; Mogilatenko, A.; Weyers, M.; Stellmach, J.; Wernicke, T.; Kneissl, M.; Yang, Z.; Chua, C.L.; et al. Modulated epitaxial lateral overgrowth of AlN for efficient UV LEDs. IEEE Photonics Technol. Lett. 2012, 24, 1603-1605. [CrossRef]

74. Liu, C.; Shields, P.A.; Denchitcharoen, S.; Stepanov, S.; Gott, A.; Wang, W.N. Pulsed epitaxial lateral overgrowth of GaN by metalorganic vapour phase epitaxy. J. Cryst. Growth 2007, 300, 104-109. [CrossRef]

75. Kueller, V.; Knauer, A.; Zeimer, U.; Rodriguez, H.; Mogilatenko, A.; Kneissl, M.; Weyers, M. (Al,Ga) N overgrowth over AlN ridges oriented in [11-20] and [1-100] direction. Phys. Stat. Sol. C 2011, 8, 2022-2024. [CrossRef]

76. Jain, R.; Sun, W.; Yang, J.; Shatalov, M.; Hu, X.; Sattu, A.; Lunev, A.; Deng, J.; Shturm, I.; Bilenko, Y.; et al. Migration enhanced lateral epitaxial overgrowth of AlN and AlGaN for high reliability deep ultraviolet light emitting diodes. Appl. Phys. Lett. 2008, 93, 051113. [CrossRef]

77. Tomiya, S.; Funato, K.; Asatsuma, T.; Hino, T.; Kijima, S.; Asano, T.; Ikeda, M. Dependence of crystallographic tilt and defect distribution on mask material in epitaxial lateral overgrown GaN layers. Appl. Phys. Lett. 2000, 77, 636-638. [CrossRef]

78. Xie, J.; Chevtchenko, S.A.; Özgür, Ü.; Morkoç, H. Defect reduction in GaN epilayers grown by metal-organic chemical vapor deposition with in situ $\mathrm{SiN}_{\mathrm{x}}$ nanonetwork. Appl. Phys. Lett. 2007, 90, 262112. [CrossRef]

79. Xie, J.; Özgür, Ü.; Fu, Y.; Ni, X.; Morkoç, H.; Inoki, C.; Kuan, T.; Foreman, J.; Everitt, H. Low dislocation densities and long carrier lifetimes in $\mathrm{GaN}$ thin films grown on a $\mathrm{SiN}_{\mathrm{x}}$ nanonetwork. Appl. Phys. Lett. 2007, 90, 041107. [CrossRef]

80. Forghani, K.; Klein, M.; Lipski, F.; Schwaiger, S.; Hertkorn, J.; Leute, R.A.R.; Scholz, F.; Feneberg, M.; Neuschl, B.; Thonke, K.; et al. High quality AlGaN epilayers grown on sapphire using $\mathrm{SiN}_{\mathrm{x}}$ interlayers. J. Cryst. Growth 2011, 315, 216-219. [CrossRef]

81. Katona, T.M.; Cantu, P.; Keller, S.; Wu, Y.; Speck, J.S.; DenBaars, S.P. Maskless lateral epitaxial overgrowth of high-aluminum-content $\mathrm{Al}_{\mathrm{x}} \mathrm{Ga}_{1-\mathrm{x}} \mathrm{N}$. Appl. Phys. Lett. 2004, 84, 5025-5027. [CrossRef]

82. Heikman, S.; Keller, S.; Newman, S.; Wu, Y.; Moe, C.; Moran, B.; Schmidt, M.; Mishra, U.K.; Speck, J.S.; DenBaars, S.P. Epitaxial lateral overgrowth of high Al composition AlGaN alloys on deep grooved $\mathrm{SiC}$ substrates. Jpn. J. Appl. Phys. 2005, 44, L405. [CrossRef]

83. Kamber, D.S.; Wu, Y.; Letts, E.; DenBaars, S.P.; Speck, J.S.; Nakamura, S.; Newman, S.A. Lateral epitaxial overgrowth of aluminum nitride on patterned silicon carbide substrates by hydride vapor phase epitaxy. Appl. Phys. Lett. 2007, 90, 122116. [CrossRef]

84. Hirayama, H.; Norimatsu, J.; Noguchi, N.; Fujikawa, S.; Takano, T.; Tsubaki, K.; Kamata, N. Milliwatt power 270 nm-band AlGaN deep-UV LEDs fabricated on ELO-AlN templates. Phys. Stat. Sol. C 2009, 6, S474-S477. [CrossRef]

85. Zhang, Y.; Gautier, S.; Cho, C.-Y.; Cicek, E.; Vashaei, Z.; McClintock, R.; Bayram, C.; Bai, Y.; Razeghi, M. Near milliwatt power AlGaN-based ultraviolet light emitting diodes based on lateral epitaxial overgrowth of AlN on Si (111). Appl. Phys. Lett. 2013, 102, 011106. [CrossRef]

86. Mino, T.; Hirayama, H.; Takano, T.; Tsubaki, K.; Sugiyama, M. Development of $260 \mathrm{~nm}$ band deep-ultraviolet light emitting diodes on Si substrates. Proc SPIE 2013, 86251Q. [CrossRef]

87. Grandusky, J.R.; Smart, J.A.; Mendrick, M.C.; Schowalter, L.J.; Chen, K.X.; Schubert, E.F. Pseudomorphic growth of thick n-type $\mathrm{Al}_{\mathrm{x}} \mathrm{GA}_{1-\mathrm{x}} \mathrm{N}$ layers on low-defect-density bulk AlN substrates for UV LED applications. J. Cryst. Growth 2009, 311, 2864-2866. [CrossRef]

88. Wunderer, T.; Chua, C.L.; Yang, Z.; Northrup, J.E.; Johnson, N.M.; Garrett, G.A.; Shen, H.; Wraback, M. Pseudomorphically grown ultraviolet $\mathrm{C}$ photopumped lasers on bulk AlN substrates. Appl. Phys. Express 2011, 4, 092101. [CrossRef]

89. Nam, K.B.; Li, J.; Nakarmi, M.L.; Lin, J.Y.; Jiang, H.X. Unique optical properties of AlGaN alloys and related ultraviolet emitters. Appl. Phys. Lett. 2004, 84, 5264-5266. [CrossRef] 
90. Kawanishi, H.; Senuma, M.; Nukui, T. Anisotropic polarization characteristics of lasing and spontaneous surface and edge emissions from deep-ultraviolet $(\lambda \approx 240 \mathrm{~nm})$ AlGaN multiple-quantum-well lasers. Appl. Phys. Lett. 2006, 89, 041126. [CrossRef]

91. Sharma, T.K.; Naveh, D.; Towe, E. Strain-driven light-polarization switching in deep ultraviolet nitride emitters. Phys. Rev. B 2011, 84, 035305. [CrossRef]

92. Northrup, J.E.; Chua, C.L.; Yang, Z.; Wunderer, T.; Kneissl, M.; Johnson, N.M.; Kolbe, T. Effect of strain and barrier composition on the polarization of light emission from AlGaN/AlN quantum wells. Appl. Phys. Lett. 2012, 100, 021101. [CrossRef]

93. Reich, C.; Guttmann, M.; Feneberg, M.; Wernicke, T.; Mehnke, F.; Kuhn, C.; Rass, J.; Lapeyrade, M.; Einfeldt, S.; Knauer, A.; et al. Strongly transverse-electric-polarized emission from deep ultraviolet AlGaN quantum well light emitting diodes. Appl. Phys. Lett. 2015, 107, 142101. [CrossRef]

94. Raghothamachar, B.; Vetter, W.M.; Dudley, M.; Dalmau, R.; Schlesser, R.; Sitar, Z.; Michaels, E.; Kolis, J.W. Synchrotron white beam topography characterization of physical vapor transport grown AlN and ammonothermal GaN. J. Cryst. Growth 2002, 246, 271-280. [CrossRef]

95. Zhang, J.P.; Wang, H.M.; Gaevski, M.E.; Chen, C.Q.; Fareed, Q.; Yang, J.W.; Simin, G.; Khan, M.A. Crack-free thick AlGaN grown on sapphire using AlN/AlGaN superlattices for strain management. Appl. Phys. Lett. 2002, 80, 3542-3544. [CrossRef]

96. Wang, H.-M.; Zhang, J.-P.; Chen, C.-Q.; Fareed, Q.; Yang, J.-W.; Khan, M.A. AlN/AlGaN superlattices as dislocation filter for low-threading-dislocation thick AlGaN layers on sapphire. Appl. Phys. Lett. 2002, 81, 604-606. [CrossRef]

97. Xi, Y.A.; Chen, K.X.; Mont, F.; Kim, J.K.; Schubert, E.F.; Liu, W.; Li, X.; Smart, J.A. Comparative study of n-type AlGaN grown on sapphire by using a superlattice layer and a low-temperature AlN interlayer. J. Cryst. Growth 2007, 299, 59-62. [CrossRef]

98. Chitnis, A.; Zhang, J.P.; Adivarahan, V.; Shatalov, M.; Wu, S.; Pachipulusu, R.; Mandavilli, V.; Khan, M.A. Improved performance of 325-nm emission AlGaN ultraviolet light-emitting diodes. Appl. Phys. Lett. 2003, 82, 2565-2567. [CrossRef]

99. Nakarmi, M.; Kim, K.; Khizar, M.; Fan, Z.; Lin, J.; Jiang, H. Electrical and optical properties of Mg-doped $\mathrm{Al}_{0.7} \mathrm{Ga}_{0.3} \mathrm{~N}$ alloys. Appl. Phys. Lett. 2005, 86, 092108. [CrossRef]

100. Taniyasu, Y.; Kasu, M.; Makimoto, T. An aluminium nitride light-emitting diode with a wavelength of 210 nanometres. Nature 2006, 441, 325-328. [CrossRef] [PubMed]

101. Nam, K.B.; Nakarmi, M.L.; Li, J.; Lin, J.Y.; Jiang, H.X. Mg acceptor level in AlN probed by deep ultraviolet photoluminescence. Appl. Phys. Lett. 2003, 83, 878-880. [CrossRef]

102. Aoyagi, Y.; Takeuchi, M.; Iwai, S.; Hirayama, H. High hole carrier concentration realized by alternative co-doping technique in metal organic chemical vapor deposition. Appl. Phys. Lett. 2011, 99, 112110. [CrossRef]

103. Korotkov, R.; Gregie, J.; Wessels, B. Electrical properties of $p$-type GaN: Mg codoped with oxygen. Appl. Phys. Lett. 2001, 78, 222-224. [CrossRef]

104. Chen, Y.; Wu, H.; Han, E.; Yue, G.; Chen, Z.; Wu, Z.; Wang, G.; Jiang, H. High hole concentration in $p$-type AlGaN by indium-surfactant-assisted Mg-delta doping. Appl. Phys. Lett. 2015, 106, 162102. [CrossRef]

105. Nakarmi, M.L.; Kim, K.H.; Li, J.; Lin, J.Y.; Jiang, H.X. Enhanced $p$-type conduction in GaN and AlGaN by

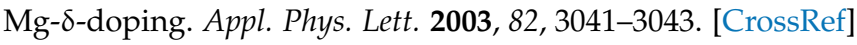

106. Allerman, A.A.; Crawford, M.H.; Miller, M.A.; Lee, S.R. Growth and characterization of Mg-doped AlGaN-AlN short-period superlattices for deep-UV optoelectronic devices. J. Cryst. Growth 2010, 312, 756-761. [CrossRef]

107. Cheng, B.; Choi, S.; Northrup, J.E.; Yang, Z.; Knollenberg, C.; Teepe, M.; Wunderer, T.; Chua, C.L.; Johnson, N.M. Enhanced vertical and lateral hole transport in high aluminum-containing AlGaN for deep ultraviolet light emitters. Appl. Phys. Lett. 2013, 102, 231106. [CrossRef]

108. Kakanakova-Georgieva, A.; Nilsson, D.; Stattin, M.; Forsberg, U.; Haglund, Å.; Larsson, A.; Janzén, E. Mg-doped $\mathrm{Al}_{0.85} \mathrm{Ga}_{0.15} \mathrm{~N}$ layers grown by hot-wall MOCVD with low resistivity at room temperature. Phys. Stat. Sol. 2010, 4, 311-313. [CrossRef]

109. Nilsson, D. Doping of High-Al-Content AlGaN Grown by MOCVD. Ph.D. Thesis, Linköping University, Linköping, Swede, 2014. 
110. Taniyasu, Y.; Kasu, M.; Kobayashi, N. Intentional control of n-type conduction for Si-doped AlN and $\mathrm{Al}_{\mathrm{x}} \mathrm{Ga}_{1-\mathrm{x}} \mathrm{Nwith}$ high $\mathrm{Al}$ content. Phys. Stat. Sol. B 2002, 234, 845-849. [CrossRef]

111. Taniyasu, Y.; Kasu, M.; Kobayashi, N. Intentional control of n-type conduction for Si-doped AlN and $\mathrm{Al}_{\mathrm{x}} \mathrm{Ga}_{1-\mathrm{x}} \mathrm{N}(0.42 \leq \mathrm{x}<1)$. Appl. Phys. Lett. 2002, 81, 1255-1257.

112. Mehnke, F.; Wernicke, T.; Pingel, H.; Kuhn, C.; Reich, C.; Kueller, V.; Knauer, A.; Lapeyrade, M.; Weyers, M.; Kneissl, M. Highly conductive $\mathrm{n}-\mathrm{Al}_{\mathrm{x}} \mathrm{Ga}_{1-\mathrm{x}} \mathrm{N}$ layers with aluminum mole fractions above $80 \%$. Appl. Phys. Lett. 2013, 103, 212109. [CrossRef]

(c)

(C) 2017 by the authors. Licensee MDPI, Basel, Switzerland. This article is an open access article distributed under the terms and conditions of the Creative Commons Attribution (CC BY) license (http://creativecommons.org/licenses/by/4.0/). 